\title{
Dietary effects on gut microbiota of the mesquite lizard Sceloporus grammicus (Wiegmann, 1828) across different altitudes
}

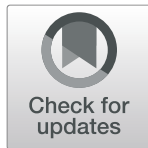

\author{
Nina Montoya-Ciriaco', Selene Gómez-Acata², Ligia Catalina Muñoz-Arenas', Luc Dendooven², \\ Arturo Estrada-Torres ${ }^{3}$, Aníbal H. Díaz de la Vega-Pérez ${ }^{4^{*}}$ and Yendi E. Navarro-Noya ${ }^{4^{*}}$
}

\begin{abstract}
Background: High-altitude ecosystems are extreme environments that generate specific physiological, morphological, and behavioral adaptations in ectotherms. The shifts in gut microbiota of the ectothermic hosts as an adaptation to environmental changes are still largely unknown. We investigated the food ingested and the bacterial, fungal, and protistan communities in feces of the lizard Sceloporus grammicus inhabiting an altitudinal range using metabarcoding approaches.

Results: The bacterial phyla Bacteroidetes and Firmicutes, and the genera Bacteroides and Parabacteroides dominated the core fecal bacteriome, while Zygomycota and Ascomycota, and the species Basidiobolus ranarum and Basidiobolus magnus dominated the core fecal mycobiome. The diet of S. grammicus included 29 invertebrate families belonging to Arachnida, Chilopoda, and Insecta. The diversity and abundance of its diet decreased sharply at high altitudes, while the abundance of plant material and Agaricomycetes was significantly higher at the highest site. The composition of the fecal microbiota of S. grammicus was different at the three altitudes, but not between females and males. Dietary restriction in S. grammicus at $4150 \mathrm{~m}$ might explain the high fecal abundance of Akkermansia and Oscillopira, bacteria characteristic of long fasting periods, while low temperature favored B. magnus. A high proportion of bacterial functions were digestive in S. grammicus at 2600 and 3100, while metabolism of aminoacids, vitamins, and key intermediates of metabolic pathways were higher at $4150 \mathrm{~m}$. Different assemblages of fungal species in the lizard reflect differences in the environments at different elevations. Pathogens were more prevalent at high elevations than at the low ones.
\end{abstract}

Conclusions: Limiting food resources at high elevations might oblige S. grammicus to exploit other food resources and its intestinal microbiota have degradative and detoxifying capacities. Sceloporus grammicus might have acquired $B$. ranarum from the insects infected by the fungus, but its commensal relationship might be established by the quitinolytic capacities of $B$. ranarum. The mycobiome participate mainly in digestive and degradative functions while the bacteriome in digestive and metabolic functions.

Keywords: Altitudinal gradient, Ectothermic vertebrate, Fecal microbiota, High-mountain ecosystem, Intestinal microbiota, Microbiome, Mycobiome

\footnotetext{
* Correspondence: anibal.helios@gmail.com; nyendi@hotmail.com

${ }^{4}$ Cátedras CONACyT, Universidad Autónoma de Tlaxcala, Tlaxcala, México

Full list of author information is available at the end of the article
}

(c) The Author(s). 2020 Open Access This article is distributed under the terms of the Creative Commons Attribution 4.0 International License (http://creativecommons.org/licenses/by/4.0/), which permits unrestricted use, distribution, and reproduction in any medium, provided you give appropriate credit to the original author(s) and the source, provide a link to the Creative Commons license, and indicate if changes were made. The Creative Commons Public Domain Dedication waiver (http://creativecommons.org/publicdomain/zero/1.0/) applies to the data made available in this article, unless otherwise stated. 


\section{Background}

The symbiotic relationship between vertebrate hosts and their intestinal microbiota is complex and has affected significantly the ecology and evolution of both [1]. Understanding the role of gut microbiota in the evolution of their vertebrate host is an outstanding question and the focus of much current research. The primary function of the gut is to obtain nutrients and gut microbiota play therein a crucial role, but they contribute also to the overall health of the vertebrate host. Experimental and comparative studies have found that gut microbial communities contribute to balancing energy, physiology, reproduction, immunity, organ development, behavior, and life history of the host [1-4]. Conversely, environmental factors, such as diet and population density, and host traits, such as infections and genetics, may affect the microbial gut communities [5-7].

Reptiles represent $17 \%$ of all vertebrate species and the order of Squamata contains almost 8000 species. Reptiles are ideal to determine the effect of temperature increases as a result of climate change and habitat degradation as they depend heavily on specific environmental conditions, i.e., they are ectotherms [8]. Ambient temperature determines characteristics of ectotherms, such as body size, reproduction, offspring, diet, metabolism, behavior, locomotion, and survival [9-11]. Ectotherms have a wide range of physiological adaptations that vary within members of the same species, but living in different conditions. Mountainous ecosystems provide a natural gradient of different environmental conditions as the temperature decreases with $0.6{ }^{\circ} \mathrm{C}$ per $100 \mathrm{~m}$ a.s.l., which allow to study the effect of these conditions on the gut microbial biota of ectotherms along the altitude gradient.

Sceloporus grammicus Wiegmann, 1828 (Squamata order), the mesquite spiny lizard, is an insectivore with a tendency to feed on Coleoptera and Hymenoptera [12]. The distribution of S. grammicus extends from southern Texas in the USA to southern Oaxaca in Mexico. It inhabits a diversity of environments ranging in altitude from 1500 to $4400 \mathrm{~m}$ a.s.l. and could be the most widespread and adaptable lizard in Mexico [12, 13].

In the National Park "La Malinche," a volcano of the Trans-Mexican Volcanic Belt (TMVB), mesquite spiny lizards can be found up to $4200 \mathrm{~m}$ a.s.l. [14]. The body temperature of $S$. grammicus decreases with increasing elevation. These extreme environmental conditions impose a high cost of thermoregulation. A wide range of physiological and behavioral strategies allows this species to successfully inhabit high-mountain ecosystems [15]. Environmental temperature has been reported to affect gut microbiota in ectotherms. Kohl and Yahn [16] found that temperature affected significantly the microbial community structure in the gut of tadpoles. Bestion et al. [6] used a semi-natural experiment to study the effect of temperature on the gut microbiota of the Zootoca vivipara lizard and found a 34\% diversity loss at high temperatures. Living at high altitudes also alters the availability of food that changes the lizards' diet, which will also require physiological adaptations and will certainly affect the gut microbiota. The gut mass of animals is proportional to the altitude reflecting an adaptation of digestive and absorptive functions [17]. Zhang et al. [18] reported significant changes in the intestinal bacterial composition of the toad-headed lizard Phrynocephalus vlangalii from three different altitudes in the Tibetan Plateau.

However, we still lack an understanding of the role of exogenous factors on the gut microbiota in ectotherms in relation with their ecophysiology. These changes in the gut microbiota might aid the host in adapting to the high altitude environmental conditions. It can be assumed that changes in the gastrointestinal traits of evolving vertebrates selected for essential taxa altering the gut microbiome profiles [1]. The gut microbiota is composed mostly of bacteria, fungi, nematodes, and viruses. Fungi might play an important role in the food degradation considering the insectivorous diet of $S$. grammicus. However, the fungal component, the mycobiome, has received little attention compared to bacteria. In the gut of the highland lizards, fungal taxa might aid in the digestion of food while bacteria in nutrient adsorption.

In this study, we used metabarcoding approaches to study the bacterial, fungal, and protistan communities, and the ingested food in feces of S. grammicus living between 2600 and $4150 \mathrm{~m}$ a.s.l. in a high-mountain ecosystem. The functional profile prediction of the fecal bacterial communities was done by ancestral reconstruction of the bacterial taxonomic assemblage to obtain insights into the functionalities of the resident bacterial biota.

\section{Methods \\ Pilot study}

The study area was located in the territory of the National Park "La Malinche" (NPLM) (N 19, 14' W $98^{\circ}$ $02^{\prime}$ ). Four adult individuals (two males and two females) were collected from the NPLM at $4150 \mathrm{~m}$ a.s.l. on 22th June 2015. Lizards were taken to the laboratory in Tlaxcala city, and maintained individually in sterile boxes until feces were obtained. Feces were collected in sterile conditions, added separately to $1.5 \mathrm{ml}$ sterile polypropylene tubes, frozen immediately at $-20{ }^{\circ} \mathrm{C}$, and extracted for DNA the next day. Individuals were dissected in sterile conditions and the gastrointestinal tract was collected and placed in a sterile tube. 
All laboratory analyses were done under strict sterile conditions. The feces and gastrointestinal tracts were extracted for metagenomic DNA as follows. First, the gastrointestinal tract tissue was macerated with a sterile pistil in tubes containing $3 \mathrm{ml}$ buffer $(0.15 \mathrm{M} \mathrm{NaCl}, 0.1$ M EDTA [pH 8.0]), weighted (varying between 126 and $580 \mathrm{mg}$ ), and divided equally over three tubes. Feces were washed twice with 1-ml decahydrated tetrasodium pyrophosphate $0.15 \mathrm{M}$ and washed twice with phosphate buffer $\mathrm{pH} 80.15 \mathrm{M}$. Three different techniques were used to extract DNA from the samples. The first method consisted in a chemical and thermal shock of the cells [19]. Cells were enzymatically lysed in the second method [20], while a detergent solution and mechanic disruption for cell lysis was used in the third method [21]. This last method promotes the lysis of filamentous fungi and yeast. The DNA obtained from the three extraction methods was pooled so that one DNA sample was obtained and used for preparing the amplicon libraries. Blank controls were included in each extraction protocol. These negative controls were pooled and verified for contamination by gel electrophoresis and $16 \mathrm{~S}$ rRNA PCR. Amplicon libraries of V3-V4 regions of $16 \mathrm{~S}$ rRNA genes were obtained using the primers described by Klindworth et al. [22]. The 300-pb paired-end (PE) MiSeq runs (Illumina) were done by Macrogen Inc. (DNA Sequencing Service, Seoul, Korea).

The bacterial community composition of the gastrointestinal tract and feces were compared and as the species turnover was $46.9 \pm 3.3 \%$; no $S$. grammicus individuals had to be sacrificed to study their gut microbiota.

\section{Sites of study and fecal sampling}

The lizards were collected at 2600, 3100, and $4150 \mathrm{~m}$ a.s.l. and considered the Low-2600, Medium-3100, and High-4150 zone. The Low-2600 zone is characterized by a temperate and semi-arid climate with mean air temperature of $14.5 \pm 6.6^{\circ} \mathrm{C}$ and mean relative humidity $58.2 \pm 28.8 \%$ [15]. Cultivation of maize (Zea mays L.) was predominant in this area and lizards were collected from an abandoned building. Lizards in this zone weight on average $6.9 \mathrm{~g}$ and their mean snout to vent length (SVL) was $60.5 \mathrm{~mm}$. The Medium-3100 zone is characterized by a semi-cold and sub-humid climate. The mean air temperature is $9.5 \pm 5.4{ }^{\circ} \mathrm{C}$ and mean relative humidity is $73.8 \pm 22.36 \%$. The vegetation contained mainly pine (Pinus montezumae Lamb) and fir (Abies religiosa Kunth). Lizards in this zone weight on average $6.6 \mathrm{~g}$ and their SVL measure was $58 \mathrm{~mm}$. The High4150 zone was covered by alpine bunchgrasses (Festuca L., Calamagrostis Adans., and Muhlenbergia Shreb.) and is defined as a cold weather regimen [23]. This is a harsh environment for lizards and considered thermally restrictive, i.e., mean air temperature is $6.8 \pm 6.6^{\circ} \mathrm{C}$ and mean relative humidity is $77.8 \pm 19.6 \%$. Lizards of this zone weight $3.8 \mathrm{~g}$ and their SVL was $49.9 \mathrm{~mm}$ [15].

A total of 96 adults S. grammicus males and females were collected (Table 1). The lizards were collected manually, stored individually in sanitized boxes, and taken to the Research Station "La Malinche" (19 $14^{\circ}$ '

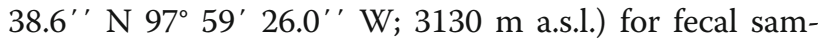
pling. Lizards were marked on their leg scales with medical cautery unit to avoid recapture. At the research station, lizards were maintained at $20-25{ }^{\circ} \mathrm{C}$ individually in sterile boxes $<12 \mathrm{~h}$ with natural periods of day/night until feces were obtained from each individual. Feces were collected under strict sterile conditions. After collection, the feces were stored and transported on ice $(<4$ ${ }^{\circ} \mathrm{C}$ ) to the laboratory in Tlaxcala city. They were kept at $-20{ }^{\circ} \mathrm{C}$ for less than a week until extracted for DNA. After the feces were obtained, all lizards were released at their place of capture.

\section{Metabarcoding analysis of the $16 \mathrm{~S}$ rRNA, $18 \mathrm{~S}$ rRNA, and coxl genes and ITS region}

The metagenomic DNA of the lizard feces was obtained by three lysis methods as mentioned before. The variable regions V1-V6 of 16S rRNA gene were amplified with primers 8-F (5'-CCA TCT CAT CCC TGC GTC TCT CCG-3') and 949-R (5'-CCT ATC CCC TGT GTG CCT TGG CAG TCT CAG-3') [19]. The 18S rRNA

Table 1 Number of individuals of Sceloporus grammicus sampled per population

\begin{tabular}{|c|c|c|c|c|}
\hline Population & Geographic location & Altitude & Date of sampling & Number of individuals \\
\hline \multirow[t]{2}{*}{ Low-2100 } & \multirow{2}{*}{$\begin{array}{l}\text { N } 19^{\circ} 12^{\prime} 32^{\prime \prime} \\
\text { W } 97^{\circ} 55^{\prime} 36^{\prime \prime}\end{array}$} & \multirow[t]{2}{*}{2,653} & \multirow[t]{2}{*}{ August 21-23 2015} & 23 Females \\
\hline & & & & 22 Males \\
\hline \multirow[t]{2}{*}{ Medium-3100 } & \multirow{2}{*}{$\begin{array}{l}\text { N } 19^{\circ} 14^{\prime} 35^{\prime \prime} \\
\text { W } 97^{\circ} 59^{\prime} 25^{\prime \prime}\end{array}$} & \multirow[t]{2}{*}{3,124} & \multirow[t]{2}{*}{ October 18-20 2015} & 14 Females \\
\hline & & & & 10 Males \\
\hline \multirow[t]{2}{*}{ High-4150 } & \multirow{4}{*}{$\begin{array}{l}\text { N } 19^{\circ} 14^{\prime} 03^{\prime \prime} \\
\text { W } 98^{\circ} 01^{\prime \prime} 43^{\prime \prime}\end{array}$} & \multirow[t]{4}{*}{4,158} & \multirow[t]{4}{*}{ September 16-19 2015} & 18 Females \\
\hline & & & & 9 Males \\
\hline \multirow[t]{2}{*}{ Total } & & & & 55 Females \\
\hline & & & & 41 Males \\
\hline
\end{tabular}


gene was amplified with the primers nu-SSU-0817 (5'TTA GCA TGG AAT AAT RRA ATA GGA-3') and nu-SSU-1196 (5'-TCT GGA CCT GGT GAG TTT CC-3') [24]. The fungal internal transcribed spacer (ITS) ITS1-5.8S-ITS2 region was amplified with the primers ITS1F (5'-CTA CGG GIG GCW GCA G-3') [25] and ITS4R (5'-GAC TAC HVG GGT ATC TAA TCC-3') [26]. Additionally, 397 base pairs of the coxI were amplified with the primers mICOIintF $\left(5^{\prime}-\mathrm{GGW}\right.$ ACW GGW TGA ACW GTW TAY CCY CC-3') [27] and jgHCO2198 (5'-TAI ACY TCI GGR TGI CCR AAR AAY $\mathrm{CA}-3^{\prime}$ ) [28]. All primers used contained the adapter for sequencing platform and $8 \mathrm{nt}$ barcodes. Amplification reactions were done in quadruplicate, pooled, and purified using QIAquick PCR purification kit according to manufacturer's instructions (QIAGEN Inc., Valencia, CA). Blank controls of PCR reagents and positive controls were included in each PCR batch. All PCR controls were pooled, purified, and included in a PCR assay to incorporate sequencing adaptors, but no amplicons were obtained. The quantification of the PCR products was done using a NanoDrop 3300 fluorospectrometer (Thermo Fisher Scientific, Waltham, MA, USA) with PicoGreen dsDNA assay (Invitrogen, Carlsbad, USA) and combined in equimolar quantities for sequencing by Macrogen Inc. Sequencing of $16 \mathrm{~S}$ rRNA libraries was done with a Roche GS-FLX Plus 454 pyrosequencer (Roche, Mannheim, Germany), while fungal ITS and $18 \mathrm{~S}$ rRNA and coxI genes with 300-pb PE MiSeq runs.

\section{Bioinformatics analysis}

Sequence analysis was done in QIIME version 1.9.1 (available at www.qiime.org). Sequences were analyzed and filtered for quality parameters. Quality filtering was done based on the following criteria: no ambiguous base calls and quality values less than 23 Phred Q score. Paired-end sequences were assembled with fastq-join method within QIIME. Operational taxonomic units (OTUs) were determined at a similarity threshold of $97 \%$ (OTU-97\%) with the open reference method of UCLUST [29]. Operational taxonomic units with less than two observations were eliminated. Representative sequences of each OTU-97\% $16 \mathrm{~S}$ rRNA sequences were aligned with database GreenGenes version 1210 available at http://greengenes.lbl.gov/ Download/. The taxonomy assignment was done using the Ribosomal Data Project (htpp://rdp.cme.msu.edu/classifier.jsp) [30] with $80 \%$ confidence threshold. The SILVA database version 132 (available at https://www.arb-silva. $\mathrm{de} /$ downoload/archive/qiime/) was used for the analysis of $18 \mathrm{~S}$ rRNA gene sequences. The non-redundant version of the UNITE+INSDC fungal ITS database [31] was used for analysis of the ITS region, while coxI taxonomic assignation was done with the BOLD ID Engine (available at http://v3.boldsystems.org/).

\section{Microbial diversity and statistical analysis}

The equivalent Hill numbers were calculated with the matrices of OTU abundances. The alpha diversity profile of $q=0,1$ and 2 were obtained with the MetagenomeDiversity script in $R$ [32]. All statistical analyses were done with $R$ [33]. The distance matrix UniFrac of the microbial community composition using $16 \mathrm{~S}$ rRNA and $18 \mathrm{~S}$ rRNA genes was done using Fast UniFrac [34]. A BrayCurtis distance matrix was determined for the fungal communities. The microbial community composition was explored by non-metric dimensional analysis (MDS) using the UniFrac and Bray-Curtis distance matrices, and to find differences in bacterial, fungal, and protist communities of the three populations of S. grammicus, permutational multivariate analysis of variance (perMANOVA) was done. perMANOVA tests were done with the vegan package [35]. Heat-maps were constructed with the pheatmap package [36]. Kruskal-Wallis and post-hoc Dunn's test was used to determine the effect of altitude on the relative abundance of the different microbial groups of Bacteria, Fungi, and microscopic Eukaryote with the package FSA. Linear mixed effects models were done with the nlme package and probabilities were calculated with permutational analysis based on 1000 Monte Carlo samplings [33].

\section{Functional profile prediction of fecal bacterial communities of Sceloporus grammicus}

The KEGG Orthologs functions of the metagenome were predicted using an ancestral state reconstruction algorithm with PICRUSt version 1.0.0 [37]. Briefly, OTUs of the 16S rRNA gene sequences were clustered at $95 \%$ similarity using the closed-reference strategy within QIIME and against the GreenGenes reference data base version 13.5 [38]. The OTU-table was normalized to correct the number of multiple $16 \mathrm{~S}$ rRNA gene copies using the GreenGenes reference data base version 13.5. The database KEGG Orthology (KO) [39] was used to estimate functional genes in fecal bacterial biota of $S$. grammicus. The statistics and graphics were done in STAMP [40].

\section{Results}

Preliminary study: comparison of the gut and fecal bacterial biota of Sceloporus grammicus

A total of 250,916 high-quality reads were obtained with no $S$. grammicus mitochondrial gene. Eight biological samples of four S. grammicus individuals were analyzed and grouped into 1839 OTU-97\%.

The bacterial gut biota of S. grammicus belonged to 30 different phyla, although 25 of them had relative abundance $<1 \%$. Firmicutes and Bacteroidetes dominated the bacterial community of the gut and feces of S. grammicus with Bacteroides and Parabacteroides 
the most abundant genera (Fig. 1a). The relative abundance of Peptococcaceae and Segetibacter was significantly higher in the gastrointestinal tract than in feces, while the relative abundance of Tenericutes, Peptostreptococcaceae, Clostridium, Phyllobacteriaceae, Bradyrhizobiaceae, Mollicutes RF39, Blautia, Pseudomonas, and [Mogibacteriaceae] was significantly higher in the feces than in the gastrointestinal tract $(p<0.05)$. The effective numbers of bacterial genera at $q=0,1$, and 2 diversity orders were similar in the feces and the gastrointestinal tract $(q=0, t=0.52, p$ $=0.638 ; q=1, t=0.62, p=0.575 ; q=2, t=0.41, p$ $=0.711$ ) (Fig. 1b). The bacterial community structure considering OTUs-97\% was not different significantly between feces and the gastrointestinal tract as determined with the perMANOVA analysis of the weighted UniFrac distances (pseudo- $F=0.8443 ; p=$ 0.471) (Fig. 1c).
Structure and composition of the fecal microbiota of Sceloporus grammicus along an altitudinal gradient Bacterial communities

A total of 85,480 high-quality sequences of $940 \mathrm{nt}$ long of 16S rRNA gene were obtained and 2788 OTU-97\%'s were clustered. The effective number of diversity order $q$ $=0\left({ }^{0} \mathrm{D}_{\alpha}\right)$ of Bacteria was $243 \pm 26$ in the Low-2600, 212 \pm 38 in the Medium-3100, and $232 \pm 35$ in the High4150 population (Fig. 2). The effective number of diversity order $q=1\left({ }^{1} \mathrm{D}_{\alpha}\right)$ was $154 \pm 34$ in the Low-2600, $122 \pm 47$ in the Medium-3100, and $144 \pm 49$ in the High-4150 population, while the effective number of diversity order $q=2\left({ }^{2} \mathrm{D}_{\alpha}\right)$ was $84 \pm 27,66 \pm 39$, and $84 \pm$ 42 , respectively.

The relative abundance of Verrucomicrobia was significantly higher in the High-4150 zone than in the other zones (Fig. 3a; Table 2). At lower taxonomic levels, the relative abundance of Elusimicrobiaceae was significantly

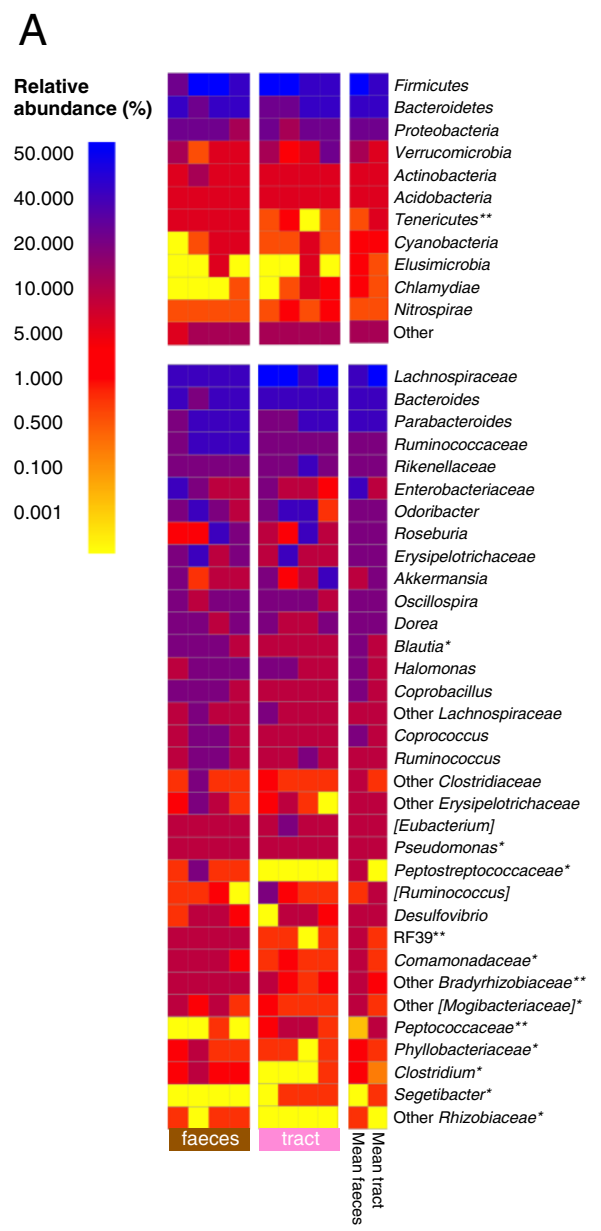

B

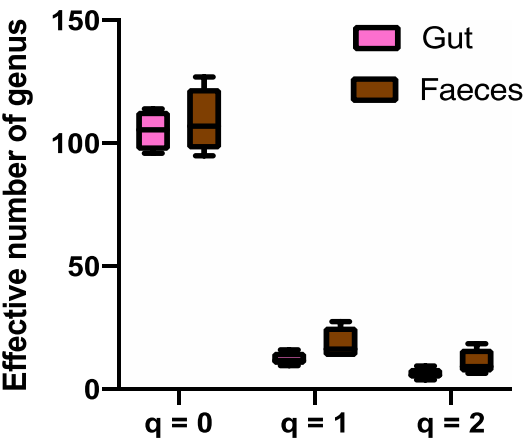

C

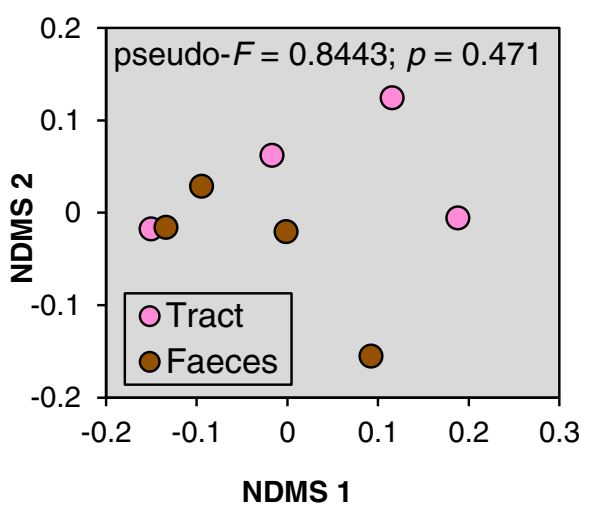

Fig. 1 Bacteria in the gastrointestinal tract and feces of Sceloporus grammicus Wiegmann. Heat-map of the relative abundance of the most abundant taxonomic groups (a), Hill numbers at diversity $q$ orders 0 , 1, and 2 of the genera (b), and non-metric dimensional analysis (MDS) of the weighted UniFrac distances of the gastrointestinal tract and feces (c). Linear mixed effects models with 1000 Monte Carlo permutations and lizard identity as random factor $\left.{ }^{*} p<0.05,{ }^{* *} p<0.01\right)$ was used to test the significant differences on the relative abundance of the different bacterial groups and perMANOVA to find differences in bacterial communities in the gastrointestinal tract and feces 

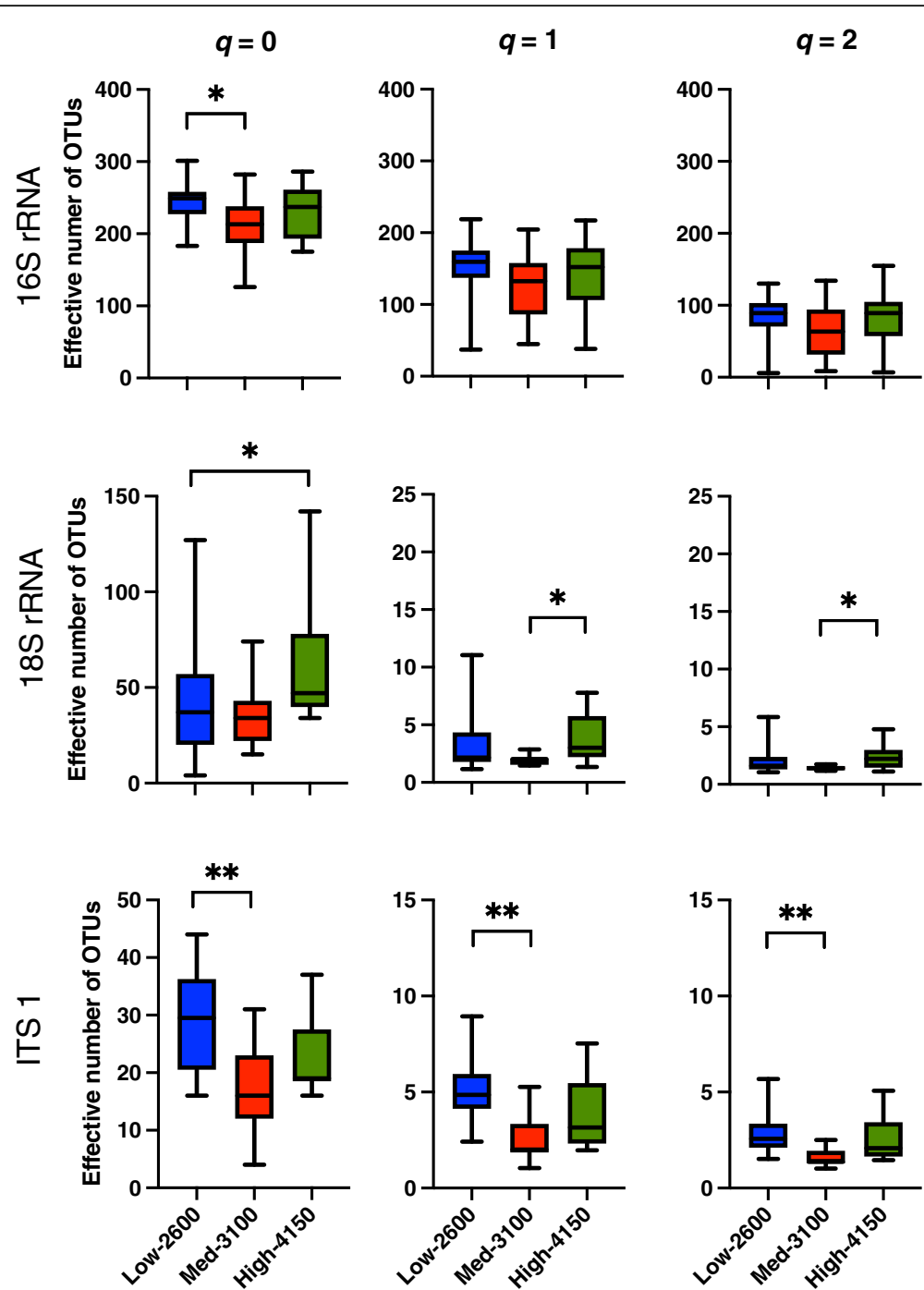

Fig. 2 True diversity (Hill numbers) at diversity $q$ orders 0,1 , and 2 of the grouped operational taxonomic units (OTUs) of the 165 rRNA gene, 185 rRNA, and ITS region of the fecal samples of Sceloporus grammicus Wiegmann found at $2600 \mathrm{~m}, 3100 \mathrm{~m}$, and $4150 \mathrm{~m}$. Significant differences between altitudes were tested by Kruskal-Wallis and post-hoc Dunn's test $\left({ }^{*} p \leq 0.05,{ }^{* *} p \leq 0.01,{ }^{* * *} p \leq 0.001\right.$ )

higher in the Low-2600 population compared to the High-4150. The relative abundance of Paenibacillus and Ralstonia was significantly higher in the Medium-3100 compared to the other altitudes, and that of Rikenellaceae, Akkermasia, Clostridium, and Oscillospira in the High-4150 population compared to the other altitudes. The fecal bacterial community composition was different significantly in the three zones as determined by a perMANOVA analysis, but sex had no significant effect (Fig. 3b, c).

\section{Micro-Eukaryotic communities}

A total 843,387 good quality sequences of the $18 \mathrm{~S}$ rRNA gene and 397 OTUs were obtained. On average, ${ }^{0} \mathrm{D}_{\alpha}$ were $41 \pm 28$ in the fecal samples of the Low- 2600 population, $37 \pm 17$ in the Medium-3100, and $63 \pm 31$ in the High-
4150 and was significantly different between Low-2600 and High- 4150 population. ${ }^{1} D_{\alpha}$ and ${ }^{2} D_{\alpha}$, which reflects heterogeneity and evenness, were significantly higher in the High-4150 than in the Medium-3100 (Fig. 2).

The foremost eukaryotic supergroup was Opisthokonta with relative abundance of $99.5 \pm 0.5 \%$, but members of SAR $(0.4 \pm 0.5 \%)$ and Archaeplastida $(0.2 \pm 0.2 \%)$ were also detected. The Opisthokonta supergroup includes Fungi and the multicellular kingdom of animals (Metazoa). Archaeplastida includes green plants and red algae while the SAR supergroup consists of Stramenopiles (diatoms, kelps, and oomycetes), Alveolata (ciliates, dinoflagellates, and parasitic apicomplexans), and Rhizaria (foraminifera, filose amoebae, and heterotrophic flagellates with filose pseudopodia). At lower taxonomic levels, the most abundant families were Basidiobales $(72.2 \pm 32.4 \%)$ and Mucorales $(8.6 \pm 19.1 \%)$ 


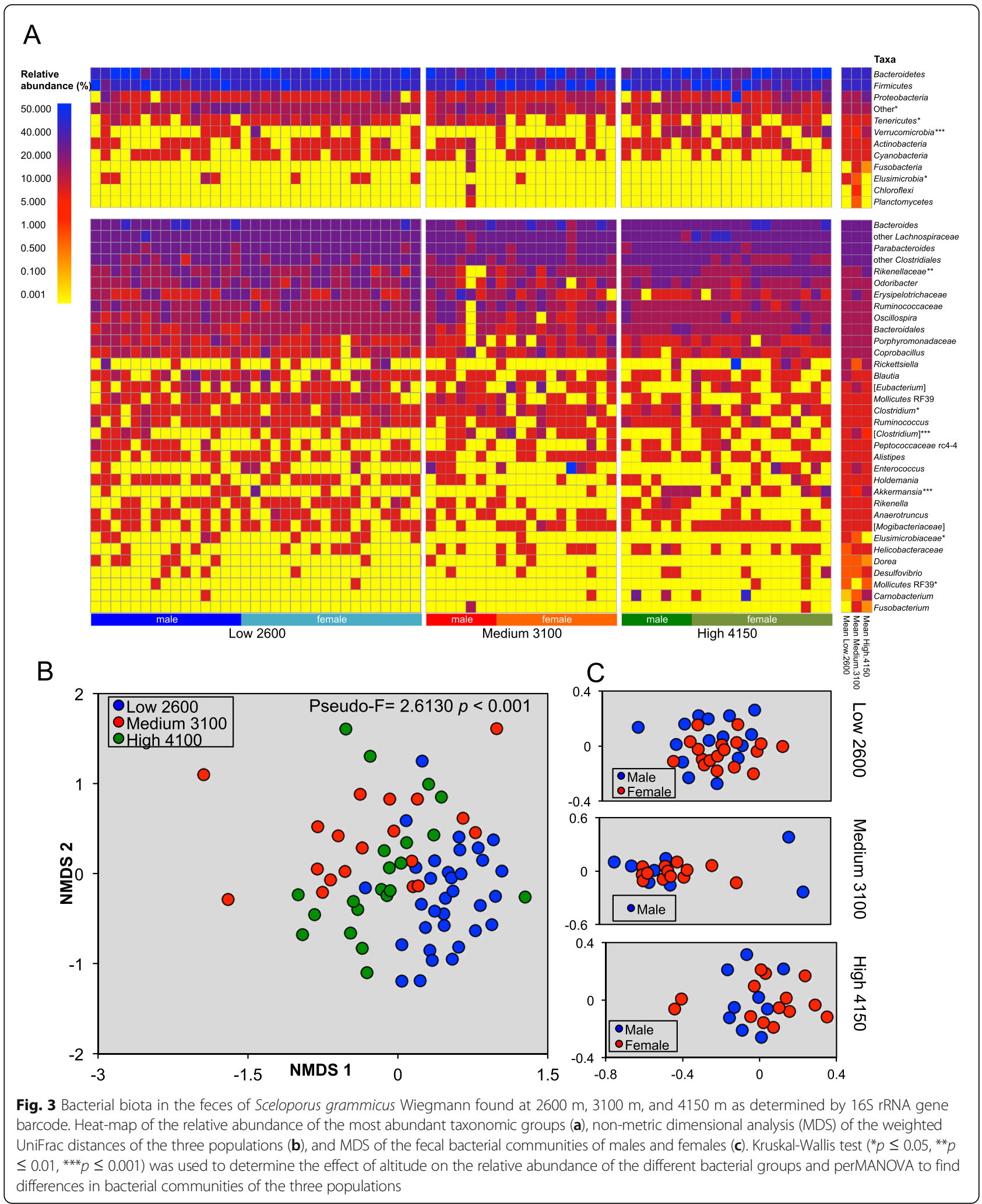

belonging to the Mucoromycota division and Saccharomycetes $(7.8 \pm 20.9 \%)$ and Eurotiomycetes $(3.4 \pm 9.8 \%)$ from the Ascomycota division (Fig. 4a). Although the 18S rRNA metabarcode detected mostly Fungi, protist, such as Proteromonas lacertae and apicomplexan parasites, such as Stenophora, Selenidium, Leidyana, Paraschneideria and Eimeria, 
Table 2 Relative abundances and statistics for microbial groups that differed significantly (Kruskal-Wallis test) in abundance between three populations of Sceloporus grammicus along an altitudinal gradient

\begin{tabular}{|c|c|c|c|c|c|c|c|c|c|c|}
\hline \multirow[t]{3}{*}{ Molecular marker } & \multirow[t]{3}{*}{ Taxonomic group } & \multicolumn{6}{|c|}{ Relative abundance (\%) } & \multicolumn{3}{|c|}{ Post-hoc Dunn's test ${ }^{a}$} \\
\hline & & \multicolumn{2}{|c|}{ Low-2600 } & \multicolumn{2}{|c|}{ Medium-3100 } & \multicolumn{2}{|c|}{ High-4150 } & \multirow[b]{2}{*}{2600 vs. 3100} & \multirow[b]{2}{*}{3100 vs. 4100} & \multirow[b]{2}{*}{2600 vs. 4100} \\
\hline & & Mean & $\mathrm{Sd}$ & Mean & $\mathrm{Sd}$ & Mean & $\mathrm{Sd}$ & & & \\
\hline \multirow[t]{20}{*}{ Bacterial 165 rRNA } & Elusimicrobia & 0.104 & 0.268 & 0.017 & 0.075 & 0 & 0 & 1.96 & 0.51 & $2.60^{*}$ \\
\hline & Tenericutes & 0.640 & 0.614 & 0.508 & 0.634 & 0.226 & 0.266 & 1.03 & 1.35 & $2.59^{*}$ \\
\hline & Verrucomicrobia & 0.238 & 1.106 & 0.069 & 0.233 & 1.037 & 1.515 & 0.94 & $-3.43^{* *}$ & $-2.92^{* *}$ \\
\hline & Eggerthella & 0.005 & 0.028 & 0.009 & 0.038 & 0.055 & 0.094 & -0.24 & $-2.35^{*}$ & $-2.92^{*}$ \\
\hline & Other Bacteroidetes & 0.560 & 0.459 & 0.336 & 0.642 & 0.647 & 0.768 & $2.60^{*}$ & -1.83 & 0.50 \\
\hline & Other Bacteroidales & 2.033 & 0.959 & 1.507 & 1.095 & 3.562 & 2.556 & 1.57 & $-3.25^{* *}$ & -2.07 \\
\hline & Other Rikenellaceae & 2.311 & 1.613 & 0.999 & 1.025 & 3.133 & 2.327 & $3.19^{* *}$ & $-3.82^{* * *}$ & -1.03 \\
\hline & Rikenellaceae & 2.549 & 1.660 & 1.619 & 1.559 & 3.733 & 3.018 & 2.07 & $-2.94^{* *}$ & -1.20 \\
\hline & Elusimicrobiaceae & 0.104 & 0.268 & 0.017 & 0.075 & 0 & 0 & 1.96 & 0.51 & $2.60^{*}$ \\
\hline & Other Bacilli & 0 & 0 & 0 & 0 & 0.047 & 0.105 & 0 & $-2.62^{*}$ & $-2.97^{* *}$ \\
\hline & Other Bacillales & 0.174 & 0.330 & 0.009 & 0.038 & 0.008 & 0.036 & $2.61^{*}$ & 0.03 & $2.73^{*}$ \\
\hline & Paenibacillus & 0 & 0 & 0.207 & 0.472 & 0 & 0 & $-3.96^{* * *}$ & $3.60^{* * *}$ & 0 \\
\hline & Other Enterococcaceae & 0.030 & 0.104 & 0.422 & 1.304 & 0.413 & 0.872 & -1.16 & -1.60 & $-3.01^{* *}$ \\
\hline & Other Clostridiaceae & 0 & 0 & 0.034 & 0.117 & 0.055 & 0.130 & -1.32 & -0.95 & $-2.45^{*}$ \\
\hline & $\begin{array}{l}\text { Clostridium } \\
\text { (Clostridiaceae) }\end{array}$ & 0 & 0 & 0.706 & 2.392 & 0.390 & 0.919 & $-3.19^{* *}$ & 0.49 & $-2.73^{*}$ \\
\hline & $\begin{array}{l}\text { Clostridium } \\
\text { (Erysipelotrichaceae) }\end{array}$ & 0.337 & 0.851 & 1.275 & 2.987 & 0.094 & 0.152 & -2.08 & $2.57^{*}$ & 0.76 \\
\hline & Achromobacter & 0 & 0 & 0.034 & 0.088 & 0.008 & 0.036 & $-2.40^{*}$ & 1.53 & -0.73 \\
\hline & Ralstonia & 0 & 0 & 0.034 & 0.088 & 0 & 0 & $-2.74^{*}$ & $2.49^{*}$ & 0 \\
\hline & Mollicutes RF39 & 0.620 & 0.615 & 0.508 & 0.634 & 0.210 & 0.254 & 0.90 & 1.45 & $2.58^{*}$ \\
\hline & Akkermansia & 0.233 & 1.107 & 0.069 & 0.233 & 1.037 & 1.515 & 0.78 & $-3.44^{* *}$ & $-3.09^{* *}$ \\
\hline \multirow[t]{17}{*}{$18 \mathrm{~S}$ rRNA } & Archaeplastida & 0.004 & 0.023 & 0.002 & 0.005 & 0.057 & 0.128 & 0.26 & $-2.87^{*}$ & $-3.79^{* * *}$ \\
\hline & Opisthokonta & 99.787 & 0.6215 & 96.942 & 10.239 & 98.18 & 3.748 & -1.64 & -1.18 & $3.25^{* *}$ \\
\hline & Bryophyta & 0 & 0 & 0.002 & 0.005 & 0.049 & 0.129 & -0.71 & -2.00 & $-3.23^{* *}$ \\
\hline & other Anurofeca & 0 & 0 & 0.075 & 0.256 & 0 & 0 & $-2.57^{*}$ & 2.33 & 0 \\
\hline & Chytridiales & 0.576 & 1.151 & 0.008 & 0.021 & 0.021 & 0.045 & 1.08 & -1.68 & $2.91^{* *}$ \\
\hline & Rhizophydiales & 0.011 & 0.058 & 0.002 & 0.005 & 0.007 & 0.011 & 0.35 & -1.78 & $2.56^{*}$ \\
\hline & $\begin{array}{l}\text { uncultured } \\
\text { Chytridiomycetes }\end{array}$ & 0.034 & 0.174 & 0.029 & 0.062 & 0.457 & 0.610 & 1.36 & -2.39 & $-4.41^{* * *}$ \\
\hline & Other Pezizomycotina & 0.015 & 0.055 & 0.008 & 0.021 & 0.123 & 0.293 & 0.06 & -2.36 & $-2.80^{*}$ \\
\hline & Eurotiomycetes & 6.558 & 13.342 & 0.026 & 0.042 & 0.586 & 0.889 & $3.98^{* * *}$ & $-2.45^{*}$ & 1.39 \\
\hline & Saccharomycetes & 5.334 & 19.615 & 8.053 & 26.098 & 12.122 & 19.489 & -0.18 & $-2.87^{*}$ & $-3.70^{* * *}$ \\
\hline & Agaricomycetes & 0 & 0 & 0.050 & 0.104 & 0.450 & 1.264 & $-2.52^{*}$ & -1.41 & $-4.50^{* * *}$ \\
\hline & Tremellomycetes & 0.025 & 0.090 & 0.024 & 0.059 & 3.655 & 9.549 & 0.53 & -2.13 & $-3.18^{* *}$ \\
\hline & Mortierellales & 0.001 & 0.003 & 0.005 & 0.008 & 0.047 & 0.093 & -1.35 & -1.84 & $-3.74^{* * *}$ \\
\hline & Umbelopsidales & 0 & 0 & 0 & 0 & 0.067 & 0.148 & 0 & $-3.69^{* * *}$ & $-4.50^{* * *}$ \\
\hline & Leidyana & 0 & 0 & 0 & 0 & 0.015 & 0.038 & 0 & $-2.51^{*}$ & $-3.06^{* *}$ \\
\hline & Colpodida & 0 & 0 & 0.008 & 0.012 & 0.016 & 0.036 & $-2.45^{*}$ & -0.33 & $-3.11^{* *}$ \\
\hline & other Poterioochromonas & 0 & 0 & 0.009 & 0.016 & 0 & 0 & $-3.71^{* * *}$ & $3.35^{* *}$ & 0 \\
\hline \multirow[t]{2}{*}{ ITS region } & Penicillium thomii & 0.020 & 0.064 & 0 & 0 & 1.425 & 3.495 & 0.51 & -2.47 & $-2.57^{*}$ \\
\hline & Humicola grisea & 0 & 0 & 0 & 0 & 0.048 & 0.096 & 0 & -1.94 & $-2.48^{*}$ \\
\hline
\end{tabular}


Table 2 Relative abundances and statistics for microbial groups that differed significantly (Kruskal-Wallis test) in abundance between three populations of Sceloporus grammicus along an altitudinal gradient (Continued)

\begin{tabular}{|c|c|c|c|c|c|c|c|c|c|c|}
\hline \multirow[t]{3}{*}{ Molecular marker } & \multirow[t]{3}{*}{ Taxonomic group } & \multicolumn{6}{|c|}{ Relative abundance (\%) } & \multicolumn{3}{|c|}{ Post-hoc Dunn's test ${ }^{a}$} \\
\hline & & \multicolumn{2}{|c|}{ Low-2600 } & \multicolumn{2}{|c|}{ Medium-3100 } & \multicolumn{2}{|c|}{ High-4150 } & \multirow[b]{2}{*}{2600 vs. 3100} & \multirow[b]{2}{*}{3100 vs. 4100} & \multirow[b]{2}{*}{2600 vs. 4100} \\
\hline & & Mean & $\mathrm{Sd}$ & Mean & $\mathrm{Sd}$ & Mean & $\mathrm{Sd}$ & & & \\
\hline & Goffeauzyma gilvescens & 0 & 0 & 0 & 0 & 1.159 & 2.758 & 0 & -1.94 & $-2.48^{*}$ \\
\hline & Naganishia friedmannii & 0 & 0 & 0 & 0 & 0.411 & 1.153 & 0 & -1.94 & $-2.48^{*}$ \\
\hline & Trichosporon insectorum & 0 & 0 & 0 & 0 & 0.097 & 0.158 & 0 & $-2.41^{*}$ & $-3.08^{* *}$ \\
\hline & Malassezia globosa & 0 & 0 & 0 & 0 & 0.121 & 0.290 & 0 & -1.94 & $-2.48^{*}$ \\
\hline & Basidiobolus ranarum & 21.413 & 12.012 & 11.957 & 6.552 & 0.290 & 0.307 & 1.66 & 1.99 & $4.36^{* * *}$ \\
\hline
\end{tabular}

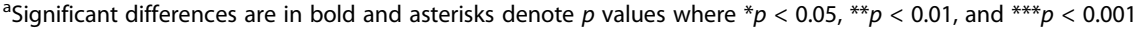

and plants (Tracheophyta) and mosses (Bryophyta) were also identified. The relative abundance of Eurotiomycetes was significantly higher in the Low-2600 population than in the other populations (Table 2). Poterioochromonas was only detected in the Medium-3100 population, and uncultured Chytridiomycetes, Umbelopsidales, Saccharomycetes, Bryophyta, Agaricomycetes, Tremellomycetes, and Leidyana were significantly higher in the High-4150 population. Overall, the microscopic Eukaryotic community structure in the feces of the lizards was different significantly between the three altitudes (Fig. 4b).

A high relative abundance of the tapeworm Cyclophyllidea $(24.5 \pm 11.7)$ was found in the Medium-3100 population and a nematode member of the Pharyngodonidae family $(0.8 \pm 2.1)$ in the High-4150 population in the metabarcoding analysis of the gene coxI (Additional file 1: Table S1). No parasites were detected in the feces of lizards found at lower altitudes.

\section{Fungal communities}

A total of 350,472 good quality sequences of the ITS15.8S-ITS2 region were obtained grouping 1547 OTU$97 \% .{ }^{0} \mathrm{D}_{\alpha}$ were $29 \pm 8$ in the fecal samples of the Low2600 population, $17 \pm 9$, in the Medium-3100, and $23 \pm$ 7 in the High-4150. True diversity at all $q$ orders $\left({ }^{0} \mathrm{D}_{\alpha}\right.$, ${ }^{1} D_{\alpha}$, and ${ }^{2} D_{\alpha}$ ) was significantly higher in the feces of the lizard population in the Low-2600 altitude than in the Medium-3100 (Fig. 2).

Zygomycota was the most abundant fungal division (relative abundance $76.7 \pm 29.4 \%$ ), followed by Ascomycota (18.6 $\pm 3.2 \%)$ and Basidiomycota $(3.3 \pm 14.3 \%)$ (Fig. 5a). Glomeromycota, Chytridiomycota, and Rozellomycota were also detected, although with a relative abundance $<1 \%$. The most abundant species were Basidiobolus magnus (62.0 $\pm 27.0 \%)$, Basidiobolus ranarum (14.7 $\pm 13.1 \%)$, Tetrapisispora fleetii (4.8 $\pm 16.3 \%)$, and Talaromyces duclauxii $(3.6 \pm 10.3 \%)$. The relative abundance of $B$. ranarum was significantly higher in the Low-2600 and Medium-3100 populations than in the High-4150 population, while that of Trichosporon insectorum, Penicillium thomii, Humicola grisea, Goffeauzyma gilvescens, Naganishia friedmannii, and Malassezia globosa were significantly higher in the High-4150 than in the population at lower altitudes (Table 2).

Fungal sequences of the coxI gene of six genera of Ascomycetes, two of Basidiomycetes, and one (Lichtheimia ramosa) of Zygomycetes were also retrieved. Six of them, i.e., Penicillium spp. (P. brevicompactum, P. coprobium, $P$. chrysogenum, $P$. commune, $P$. crustosum, and P. griseofulvum), Leohumicola, and Rhodotorula were significantly higher in the feces of the lizards found in the Low-2600 than in the Medium-3100 and High-4150 population, while Candida, L. ramosa, and P. citrinum were significantly higher in the High-4150 population compared to the other two populations (Additional file 1: Table S1).

The overall structure of the fecal fungal communities, based on the ITS1 analysis, was significantly different between the Low-2600 and High-4150 S. grammicus populations (Fig. 5b).

\section{Functional profiles of bacterial communities associated with Sceloporus grammicus}

The prediction of the functional profile of bacterial communities expressed in terms of functional orthologs using the $\mathrm{KO}$ database revealed that $47.8 \%$ of the KOs were assigned to the KEGG metabolism pathway, $18.3 \%$ to genetic information processing, $15.6 \%$ to environmental information processing, $3.1 \%$ to cellular processes, and $0.7 \%$ to organismal systems (Additional file 1: Table S3). Within KEGG metabolism pathway, KOs were grouped in the modules of carbohydrates (11.9\%), amino acids (9.2\%), energy (5.6\%), cofactor and vitamins (3.9\%), nucleotides (3.8\%), and lipid metabolism (3\%). Several functions were different significantly between populations of the High4150 and Low-2600, and High-4150 and Medium-3100 populations (Fig. 6). However, no difference in functionality of the microorganisms was found in the feces of Low2600 and Medium-3100 lizard populations. For example, peptidases and nitrogen metabolism-related KOs were significantly higher in the Low-2600 and Medium-3100 populations compared to those in High-4150. The High-4150 microbiome contained a highly significant relative abundance of KOs related with metabolism of aminoacids, 


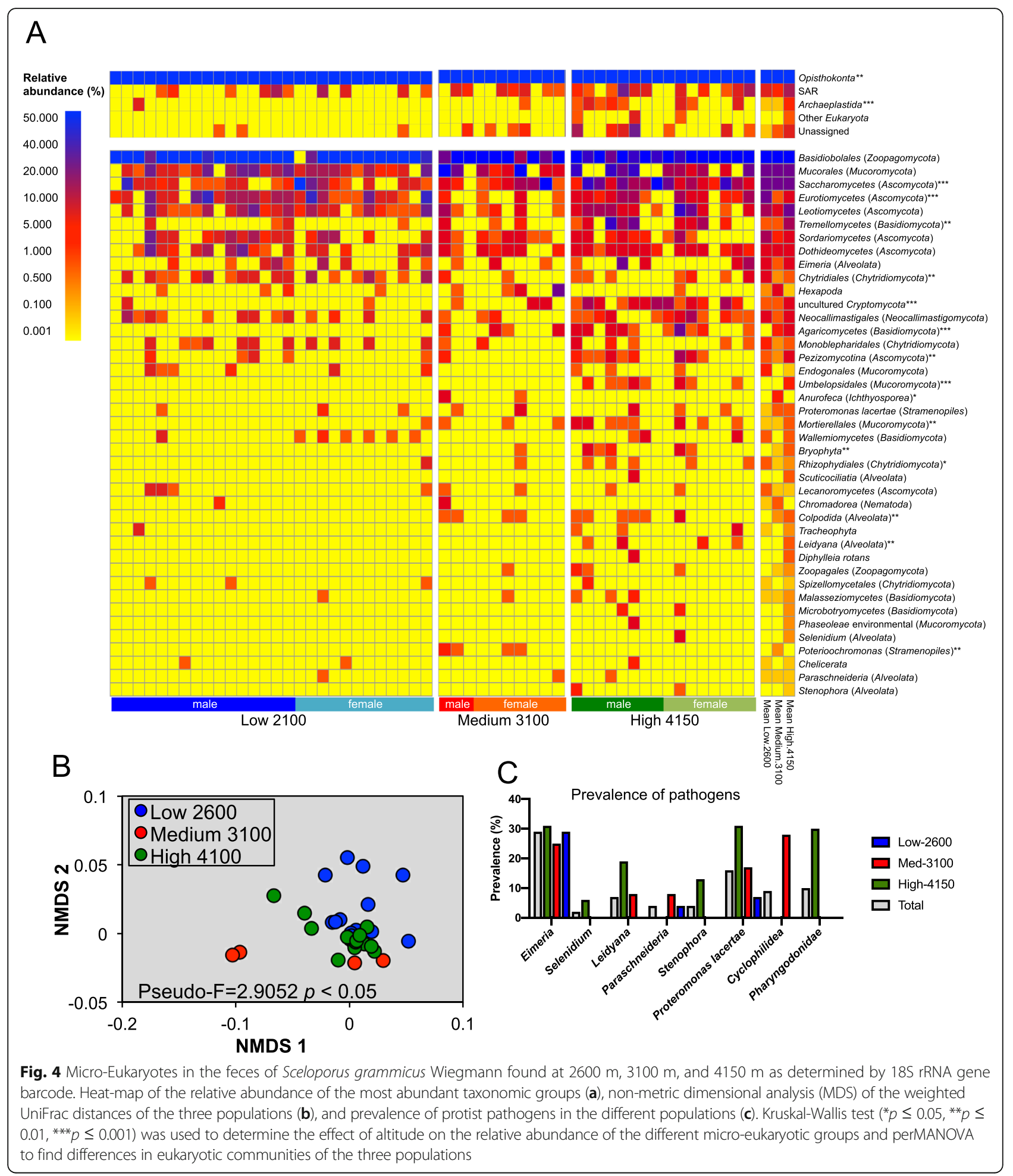

vitamins and vitamins precursors, membrane components, and key intermediates of metabolic pathways, such as tryptophan, tyrosine, aminobenzoate, retinol, fatty acids, arachidonic acid, glycerophospholipids and pyruvate, and several aromatic compounds degradation and xenobiotics metabolism via cytochrome P450. coxl metabarcoding analysis of feces of Sceloporus grammicus along an altitudinal gradient

The 41 fecal samples (15 from the Low-2600, 13 from the Medium-3100, and 13 from the High- 4150 populations) retrieved 127,795 high-quality gene coxI sequences. The sequences were clustered in 669 OTU-97\%. Of all sequences, 
A

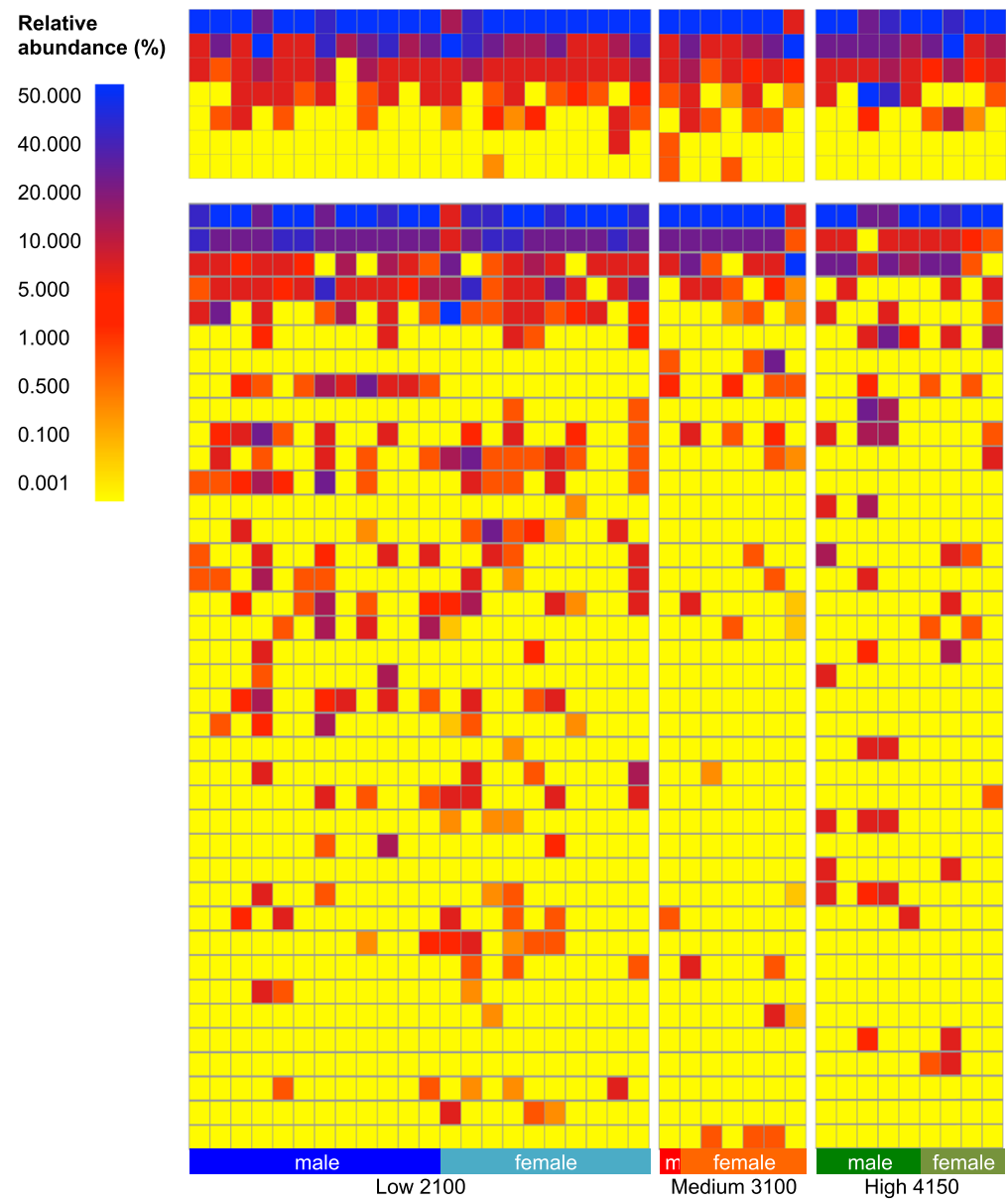

Zygomycota
Ascomycota
Unidentified Fungi
Basidiomycota
Glomeromycota
Chytridiomycota
Rozellomycota

20.000
10.000
5.000
1.000
0.500
0.100
0.001

B

C

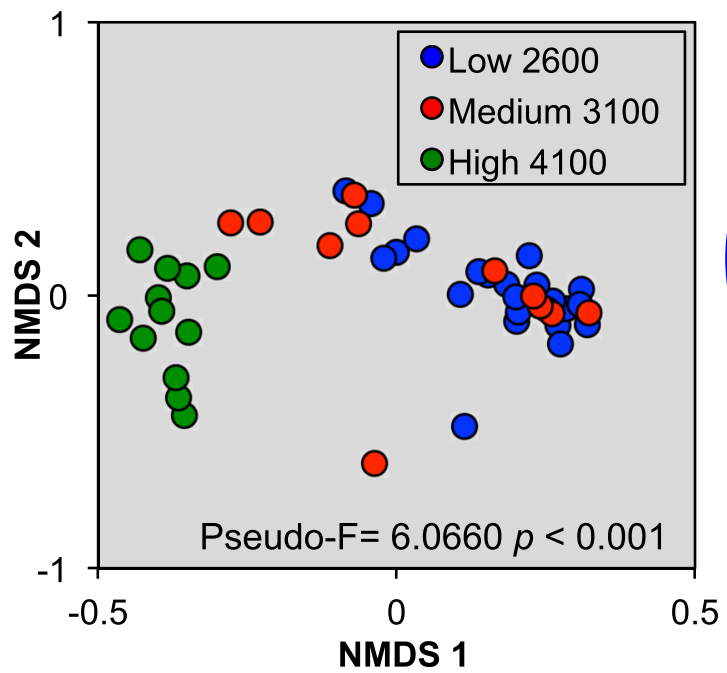

Core mycobiome $\mathbf{6 0 \%}$

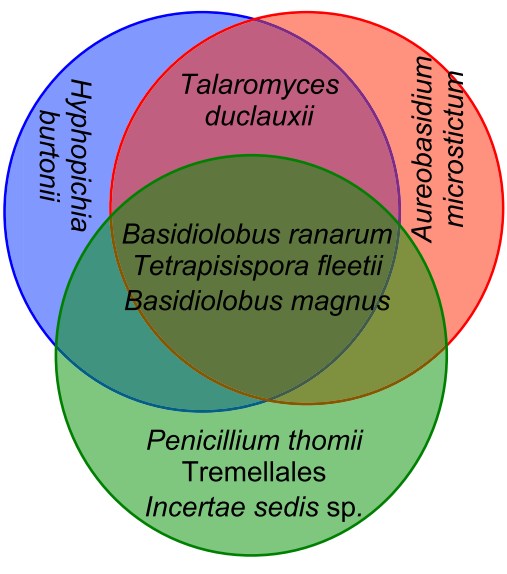

Fig. 5 (See legend on next page.) 
(See figure on previous page.)

Fig. 5 Fungi in the feces samples of Sceloporus grammicus Wiegmann found at 2600 m, 3100 m, and $4150 \mathrm{~m}$ as determined by ITS region barcode. Heat-map of the relative abundance of the most abundant taxonomic groups (a), non-metric dimensional analysis (MDS) of the BrayCurtis distances of the three populations (b), and Venn diagram of the species of the core mycobiota (c). Kruskal-Wallis test $\left({ }^{*} p \leq 0.05\right.$, ${ }^{* *} p \leq 0.01$, ${ }^{* * *} p \leq 0.001$ ) was used to determine the effect of altitude on the relative abundance of the different fungal groups and perMANOVA to find differences in fungal communities of the three populations

40.9\% belonged to Arthropoda, $7.0 \%$ to Ascomycota, $50.6 \%$ to Zygomycota, while $0.8 \%$ of the sequences remain unidentified (Additional file 1: Table S1). Four classes, i.e., Arachnida (four families), Chilopoda (one family), Insecta (24 families), and Malacostrata (one family), and 30 families were identified belonging to Arthropoda (Table 3). Of them, 25 families were found in the feces of the Low-2600, 11 in the Medium3100, and only two (Eremaeidae and Gryllidae) in the High4150 population.

\section{Discussion}

The intestinal microbiota is a complex network of bacterial, fungal, protistan, archaeal, and viral communities that play an important role in the well-being of its host. The intestinal microbiota of reptiles has been studied little and in less so under natural conditions. The microbiota composition, however, is highly relevant as it might be related to ecophysiological adaptations of ectotherms to environmental changes in the context of climate change and might help their conservation [6].

The core bacterial community of the gastrointestinal tract and feces of S. grammicus was dominated by Firmicutes and Bacteroidetes. In general, the vertebrates' gastrointestinal tract harbors a similar and conservative bacterial assemblage dominated by Firmicutes, Bacteroidetes, and Proteobacteria, with low relative abundances of other bacterial phyla [41]. The fecal microbiota of reptiles, such as herbivorous lizards, iguanas, and tortoises [42, 43], the Burmese phyton (Python molurus) [44], and the lizards Phrynocephalus vlangalii [18], Liolaemus parvus, Liolaemus ruibali, and Phymaturus williamsi [45] are dominated also by Firmicutes and Bacteroidetes. However, it has been shown that the bacterial assemblages in the gut of squamates are affected by different parameters, such as diet, captivity, digestion of particular prey items, and periods of fasting [6, 4548]. Additionally, the bacterial communities are different across gut regions [45-47]. For instance, the large intestine of the Burmese phyton was dominated by Bacteroidetes during fasting, while Firmicutes dominated during active digestion [44]. Kohl et al. [45] found that the composition of the bacterial communities in hindgut of three species of lizards was similar to that in their feces. They suggested that feces are an acceptable indicator for microbial diversity in the gut. A similar observation was found in this study. However, our conclusion was limited as we did not analyze the bacterial community across the gut regions and the sample size was small $(n=4)$.

Bacteroides and Parabacteroides were the most abundant genera in the gastrointestinal tract and feces of S. grammicus as found often in birds, mammals, reptiles, and insects [e.g., 8]. Members of Bacteroides participate in the degradation of biopolymers, mainly

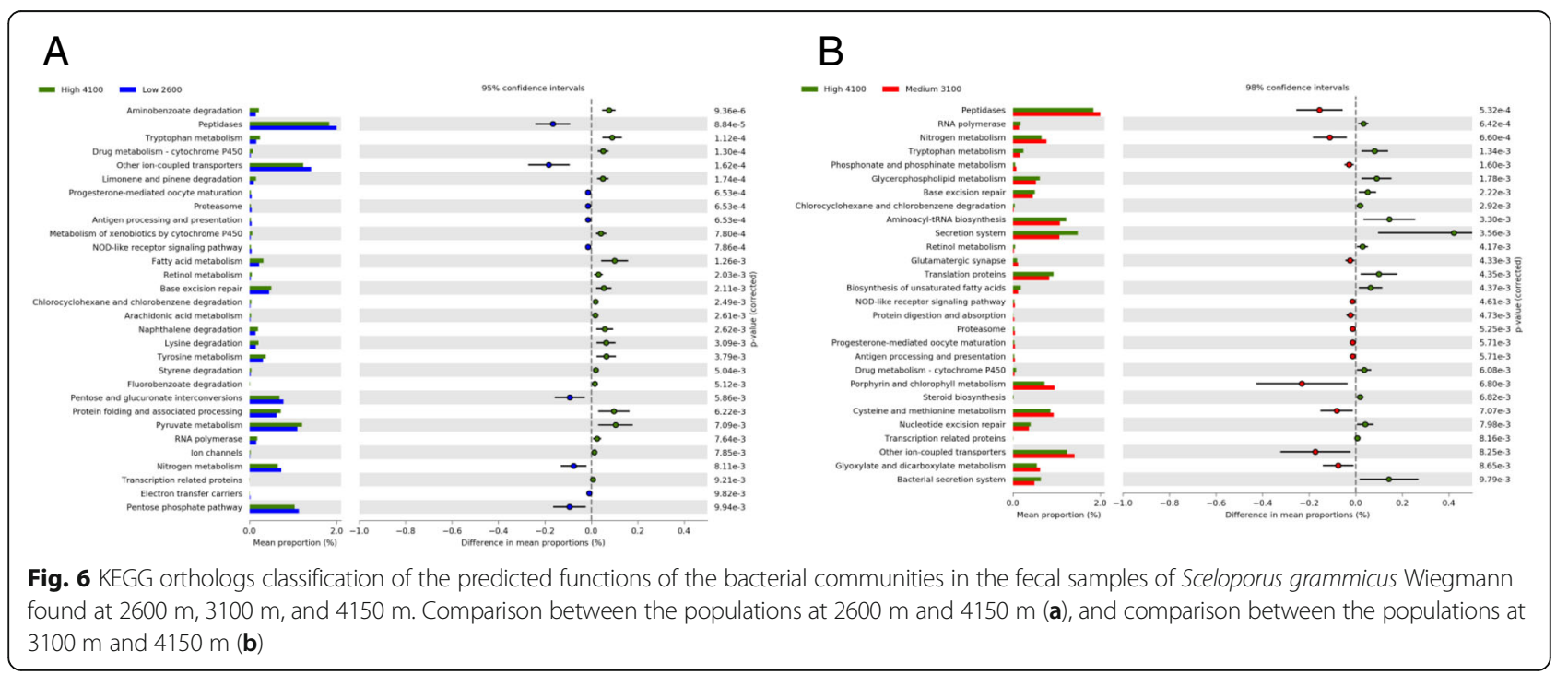


Table 3 Taxonomic assignation of the coxl gene sequences belonging to Arthropoda of the DNA from fecal samples of Sceloporus grammicus along an altitudinal gradient

\begin{tabular}{|c|c|c|c|}
\hline Taxon & 2600 masl & 3100 masl & 4150 masl \\
\hline Arachnida & $1.87^{a}$ & 1.30 & 0.25 \\
\hline Araneae & 0.04 & 0.00 & 0.00 \\
\hline Araneidae & 0.04 & 0.00 & 0.00 \\
\hline Sarcoptiformes & 1.83 & 1.30 & 0.25 \\
\hline Acaridae & 0.06 & 1.11 & 0.00 \\
\hline Eremaeidae & 0.00 & 0.00 & 0.25 \\
\hline Histiostomatidae & 0.00 & 0.19 & 0.00 \\
\hline Chilopoda & 1.45 & 0.00 & 0.00 \\
\hline Geophilomorpha & 1.45 & 0.00 & 0.00 \\
\hline Geophilidae & 1.45 & 0.00 & 0.00 \\
\hline Insecta & 52.80 & 24.38 & 0.15 \\
\hline Coleoptera & 9.73 & 13.90 & 0.00 \\
\hline Carabidae & 0.16 & 0.17 & 0.00 \\
\hline Chrysomelidae & 0.02 & 0.22 & 0.00 \\
\hline Curculionidae & 3.59 & 2.83 & 0.00 \\
\hline Lycidae & 0.15 & 0.00 & 0.00 \\
\hline Tenebrionidae & 5.82 & 10.68 & 0.00 \\
\hline Diptera & 0.34 & 0.89 & 0.00 \\
\hline Calliphoridae & 0.21 & 0.00 & 0.00 \\
\hline Limoniidae & 0.02 & 0.33 & 0.00 \\
\hline Sciaridae & 0.11 & 0.22 & 0.00 \\
\hline Hemiptera & 4.11 & 8.93 & 0.00 \\
\hline Anthocoridae & 0.07 & 2.33 & 0.00 \\
\hline Cercopidae & 2.63 & 0.00 & 0.00 \\
\hline Cicadellidae & 0.18 & 0.00 & 0.00 \\
\hline Cydnidae & 0.00 & 2.73 & 0.00 \\
\hline Cymidae & 0.49 & 0.00 & 0.00 \\
\hline Membracidae & 0.11 & 0.00 & 0.00 \\
\hline Miridae & 0.28 & 0.00 & 0.00 \\
\hline Ortheziidae & 0.27 & 0.00 & 0.00 \\
\hline Hymenoptera & 0.16 & 0.53 & 0.00 \\
\hline Formicidae & 0.10 & 0.53 & 0.00 \\
\hline Halictidae & 0.01 & 0.00 & 0.00 \\
\hline Ichneumonidae & 0.05 & 0.00 & 0.00 \\
\hline Lepidoptera & 0.07 & 0.12 & 0.00 \\
\hline Erebidae & 0.04 & 0.00 & 0.00 \\
\hline Gelechiidae & 0.03 & 0.00 & 0.00 \\
\hline Orthoptera & 36.66 & 0.01 & 0.14 \\
\hline Gryllidae & 36.66 & 0.01 & 0.14 \\
\hline Psocodea & 1.68 & 0.00 & 0.00 \\
\hline Myopsocidae & 1.63 & 0.00 & 0.00 \\
\hline Psocidae & 0.05 & 0.00 & 0.00 \\
\hline
\end{tabular}

Table 3 Taxonomic assignation of the coxl gene sequences belonging to Arthropoda of the DNA from fecal samples of Sceloporus grammicus along an altitudinal gradient (Continued)

\begin{tabular}{llll}
\hline Taxon & 2600 masl & 3100 masl & 4150 masl \\
\hline Malacostraca & 0.00 & 0.18 & 0.00 \\
Isopoda & 0.00 & 0.18 & 0.00 \\
$\quad$ Desmosomatidae & 0.00 & 0.18 & 0.00 \\
\hline
\end{tabular}

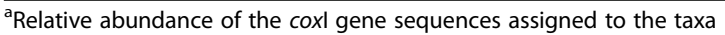

polysaccharides, and Bacteroides thetaiotaomicron regulates intestinal genes involved in absorption of nutrient and intestinal maturation [49].

A high relative abundance of Zygomycota and Ascomycota was detected in the feces of $S$. grammicus using different DNA barcodes, i.e., ITS region, 18S rRNA, and coxI. Fungi have been determined little in the gut or feces of vertebrates, even in humans. However, they have a great relevance in the symbiotic relation with the host as they have the capacity to degrade complex molecules, and participate in the fermentation and production of secondary metabolites. The core fecal mycobiome of $S$. grammicus was composed of Basidiobolus ranarum, $B$. magnus, and Tetrapisispora fletii. Basodiobolus belongs to Entomophthoromycota (Zygomycota) and is a parasitepathogen of arthropods and insects that use subtilisinlike serine proteases to degrade chitin-associated proteins in the insect procuticle [50]. It is possible that lizards ingest propagules of Basidiobolus spp. through infected insects or carrying their conidia [51]. The association of Basidiobolus spp. with the vertebrate gut, particularly reptiles and amphibians, has been reported before [52, 53]. Strains of Basidiobolus with extracellular chitinase production have been isolated from the frogs' intestine [54]. It is possible that reptiles and amphibians obtained Basidiobolus spp. from their diet. A commensal relationship of Basidiobolus spp. with S. grammicus might be linked to the chitinolitic capabilities of the fungi participating in the degradation of the exoskeleton of the arthropods that the lizard feeds on. In humans, a strong link exits between the food consumed and fungal abundance in the gut [55]. Fermentative yeasts are also an integral part of the gut mycobiota. The yeast Tetrapisispora has been associated with insects, particularly cockroaches [56, 57]. Tetrapisispora phaffii produces a killer toxin (glycoprotein Kpkt) that is lethal to other spoilage yeasts [58].

Gut Protozoa and Helminthes have been considered parasites and pathogens. However, the eukaryotic residents of the gut are often commensals and many gut Protozoa play an important role in controlling bacterial populations [59]. No core group of eukaryotic residents was detected, however, in the feces of $S$. grammicus. 


\section{Diet of Sceloporus grammicus along an altitudinal gradient}

Sceloporus grammicus has been described as an insectivore species with a tendency to feed on Coleoptera and Hymenoptera [12]. In this study we found that S. grammicus feeds mainly on Orthoptera and Coleoptera insects. Here, we confirm that with altitude the number of arthropods that S. grammicus ingests and their diversity sharply decreased. The decrease was dramatic; of the 25 families of arthropods found in the feces of the Low2600 population, only two families were detected in the High-4150 population, and the relative abundance of coxI belonging to arthropods dropped from $55.7 \%$ to only $0.4 \%$. It is well known that species richness of most arthropods and their body size decreases with increasing elevation (e.g., [60, 61]). Additionally, low temperatures limited the thermal opportunities for foraging activity of lizards at high elevations. This implies that lizards at high elevations must (1) be better at extracting the available energy from their diet, (2) reduce expenditure from their total energy budget, or (3) allocate less energy to growth. In the first scenario, the gastrointestinal microbial community must play a crucial role, while for the third scenario, Sears [62] found that a high elevation population of Sceloporus graciosus grew faster than populations at lower altitude at the expense of their metabolic expenditure.

\section{Composition of the fecal microbiota of Sceloporus grammicus along an altitudinal gradient}

Sceloporus grammicus is exposed to extreme conditions at high altitude, e.g., $4150 \mathrm{~m}$ a.s.l, such as a low partial oxygen pressure, low temperatures, high level of ultraviolet radiation, and dietary restrictions. In this study, the proportion of Akkermansia (Verrucomicrobia) increased in the feces of $S$. grammicus at high altitude. Akkermansia spp. are mucin-degrading bacteria that live in the mucus layer of the intestine [63]. In other animal models, the proportion of Akkermansia decreases with altitude, for example in the lizard P. vlangalii [18] and in the wild house mice [64]. The Tibetan antelope (Pantholops hodgsonii), which is very well adapted to high altitudes, with a vegetarian diet low in calories and vitamins also contains large proportions of Akkermansia [65]. Several studies found that Akkermansia muciniphila is highly competitive in hosts with restricted diets low in calories and nutrients as it is capable of subsisting on host mucus as a sole source of carbon and nitrogen [66]. For example, its abundance increased after fast in hamsters [67] and the Burmese phyton [44].

Similarly, the proportion of Oscillospira increased in the High-4150 population. Oscillospira has never been cultivated, so little is known of its ecological role or physiological properties in the intestinal tract; yet is frequently detected in metagenomic studies of vertebrate intestinal biota [68]. Kohl et al. [69] compared the response of gut microbiota of different vertebrates to fasting and the relative abundance of Oscillospira increased in the cecum of a bird, a fish, and a mammal during fasting. They speculated that Oscillospira degrade glycans of the host, such as fucose, sialic acids, and glucuronic acid. As such, it is more likely that dietary restriction enrich members of Oscillospira living at $4150 \mathrm{~m}$ instead of low $\mathrm{O}_{2}$ pressure and low temperature as suggested by Zhang et al. [18]. Additionally, the lizards at this high altitude were exposed to longer periods of lower temperatures than those at lower altitude, which promotes long periods of inactivity and fasting [15].

The relative abundance of Oscillospira and Clostridium, and members of Rikenellaceae and Ruminococcaceae increased in the feces of lizards from the High-4150 and the Medium-3100 populations. These bacterial groups are reported as specialists in the digestion of cellulose and are playing an essential role in the fermentation of fiber in herbivorous, including reptiles [42, 45, 70-72]. A significant number of reads of $16 \mathrm{~S}$ rRNA of chloroplast in lizards from the High-4150 populations and in a minor proportion in the Medium-3100 were detected. These data are not shown as NGS quality good practices suggest eliminating reads from chloroplast and mitochondria (https://galaxyproject.github.io/trainingmaterial/topics/metagenomics/tutorials/mothur-miseqsop/tutorial.html). Metabarcoding using $18 \mathrm{~S}$ rRNA revealed also a significantly higher proportion of Bryophyta in the High-4150 S. grammicus. Serrano-Cardozo et al. [73] found plant material in the gastrointestinal tract of Sceloporus spp. in a semiarid region of Mexico. It is possible that (1) plant tissue was accidentally digested during the capture of prey, (2) plant material originates from the intestinal content of the prey, (3) ingestion of plants might be an additional source of water, and/or (4) plant material was ingested deliberately by members of the High-4150 population as the amount of insects that can serve as food is limited. The gut biota of High-4150 S. grammicus was enriched with microorganisms specialized in plant fiber degradation (Clostridium, Rikenellaceae, and Ruminococcaceae), which would suggest that plant material was ingested deliberately. The gut bacteriome predicted functions showed also a significantly higher abundance of functions related to the degradation of several aromatic compounds and xenobiotics in the High-4150 population. This suggests that plant material was ingested deliberately and the intestinal associated bacterial biota have the capacity to degrade vegetal material and detoxify the aromatic compounds of the vegetal material.

Fungi are known to produce a diverse array of secondary metabolites. However, little is known about their 
contribution to the gut ecology. The relative abundance of $B$. ranarum was significantly higher in the Low- 2600 and Medium-3100 populations than in the High-4150, but that of $B$. magnus was similar. Basidiobolus magnus prefers nutrient poorer substrates than $B$. rararum [74] while $B$. ranarum is also a pathogen in humans as it can grow at $37{ }^{\circ} \mathrm{C}$ [51]. It is likely that the low temperature at high altitude was unfavorable for $B$. ranarum and that $B$. magnus was more competitive in the gut of the High4150 population.

The feces of the High-4150 population contained biome microorganisms of insects, e.g., Trichosporon insectorum and several Gregarinasina (Leidyana, Selenidium, and Stenophora) but a low number of coxI from insects. Trichosporon insectorum is a basidiomycete yeast and the resident of the gut of insects [75], while Gregarinasina are intracellular parasitic apicomplexan alveolates found in the intestinal epithelial cells of cockroaches, mealworms, grasshoppers, crickets, crayfishes, and centipedes [76]. We hypothesize that the High-4150 population extracts as much nutrients from their food as possible by maintaining it longer in their lumen. Many studies on vertebrates have shown that the production of digestive enzymes increased with substrate availability in the gut lumen [77]. However, increasing enzymatic and absorptive capacities is limited and correlated to the amount of food digested because of its costs.

Little is known about the role of Fungi in the gut ecosystem of reptiles. Gouba and Drancourt [78] found 221 different fungal species belonging to the phyla Ascomycota, Basidiomycota, and Zygomycota, including Basidiobolus ranarum, Penicillium spp., and Aspergillus spp. in the intestinal human microbiota. Hallen-Adams and Suhr [79] reported that only a limited number of fungal species, mostly Candida yeasts, are capable to colonize and grow in the gut of humans. In this study, different assemblages of fungal species were found in the feces of the three populations of $S$. grammicus. In the Low-2600 population, the assemblage contained members of Aspergillus, Eurotiomycetes, Talaromyces, and several Penicillium spp. and in the High-4150 population members of Penicillium spp., Candida, Goffeauzyma, Naganishia, and Malassezia yeasts. In the Med-3100 population, the fungi were mainly members of Candida. It is possible that Penicillium species contributed to the gut ecosystem as they are producers of secondary metabolites, extracellular enzymes (alginase, endoglucanase, $\beta$-glucosidase), and bioactive compounds (anti-tumor, anti-fungal, and antibacterial activity), while some species possess fatty acid synthases that fulfil numerous central biological roles in living cells $[80,81]$. It is possible that the different assemblages of yeast and anamorphic fungi might be the result of the environments that the different populations inhabit. For example, Goffeauzyma and Naganishia yeast have been reported as psychrophilic and found in extreme cold environments $[82,83]$.
In the High-4150 populations, a higher relative abundance of Agaricomycetes was found compared to the other two populations. We discard the possibility of spore contamination of the fecal samples during the collection as all samples were collected with the same cautious and under sterile conditions. It is possible that Agaricomycetes derived from the intestines of the insects. However, although fungivorous reptiles have never been reported, it is still possible that the limiting food resources of the High-4150 population might have obliged the lizards to exploit different food resources. Kohl et al. [45] investigated environmental sources that might contribute to the gut microbial communities of wild omnivorous lizards. They found that soil bacteria and the invertebrate diet did not contribute significantly to the gut communities of lizards, but the type of plants consumed did. The same was found in herbivorous desert wood rats (Neotoma lepida) [84]. There was substantial overlap between the gut microbiota of desert wood rats and the phyllosphere microbiota of their dietary plants. In the Burmese pythons, the microbes of the rodents they consumed contributed $<1 \%$ to their gut community [44].

\section{Predicted fecal bacteriome functions of Sceloporus grammicus along an altitudinal gradient}

We are aware that the PICRUSt analysis in non-model organisms should be interpreted with care. However, we found that the abundance of functional features associated with metabolism were different between the lizard populations. Peptidases and nitrogen metabolism were higher in the Low-2600 and Medium-3100 lizard populations compared to High- 4150 ones, while metabolism of aminoacids, vitamins, and key intermediates of metabolic pathways were higher in the High- 4150 bacteriome. We hypothesize that the difference in quality and quantity of the diet of S. grammicus at different altitudes affected the functional profiles of their gut bacteriome. Similarly, Wang et al. [85] found that artificially fed Barheaded geese had a higher bacterial gene content related to carbohydrate transport and metabolism, energy metabolism and coenzyme transport, and metabolism, compared to the wild ones.

\section{Alpha and beta diversity of the fecal microbiota of Sceloporus grammicus along an altitudinal gradient} Although the microbial composition varied greatly among individuals, the community composition of bacteria, micro-eukaryotes, and fungi in the feces of three populations of S. grammicus was different along the altitudinal gradient. In an experimental study with the lizard $Z$. vivipara, species richness of the gut bacterial biota decreased when they were maintained at a 2 to 3 ${ }^{\circ} \mathrm{C}$ higher temperature [6]. In S. grammicus, the bacterial diversity $\left({ }^{1} D_{\alpha}\right.$ and $\left.{ }^{2} D_{\alpha}\right)$ and richness $\left({ }^{0} D_{\alpha}\right)$ were similar along an altitudinal gradient. The Low-2600 population 
had the highest ITS phylotypes diversity compared to the other populations. We can assume that the main functions of fungal communities in the gut of the Low2600 are digestive and hydrolytic and that a high food intake promoted their high diversity. However, diversity and richness of ITS and 18S rRNA phylotypes were in general lower in the Medium-3100 population. The individuals of the Medium-3100 population had the lowest survival rates [15]. It is likely that the limited diversity of the microbiota was related with the low survival of the Medium-3100 population.

\section{Eukaryotic gut biota: friends or foes?}

Research on parasitic infections in wildlife has received increased attention for their role in extirpations and extinctions, e.g., in amphibian. Protozoa and fungi can cause severe illness. Yet many infections are often asymptomatic, probably reflecting a long co-evolutionary history. The thin line between gut pathogen and gut commensal is hard to determine as host-parasite interactions are complex, and intestinal microbiota is possibly the source of several infections [78]. Immune responses in ectothermic vertebrates are linked to ambient temperature, but the physiological activities of pathogens also [86]. It is therefore difficult to associate the presence/prevalence of commensals and/or parasites, e.g., Proteromonas lacertae, Eimeria, Lichtheimia, Pharyngodonidae nematode, and tapeworm Cyclophyllidea, in the different populations of S. grammicus with health or disease. Proteromonas lacertae (14\% prevalence in S. grammicus) is a strict anaerobic stramenopile that lives as a commensal in the posterior intestinal tract of lizards [87]. Its closest relative and human/mammal counterpart is Blastocystis, which can be found with high prevalence in healthy populations [88]. Members of Lichtheimia spp. are ubiquitously distributed fungi and saprobic decomposers of decaying organic matter in soil. Recently, they have been found to be an important emerging human pathogen and they are the second most common cause of mucormycosis in Europe and the third worldwide [51]. Lichtheimia was found with high frequency in the High-4150 population. Eimeria (7\% of prevalence in S. grammicus) is a genus of apicomplexan parasites that includes various species capable of causing coccidiosis in vertebrates. Pharyngodonidae nematodes (10\% of prevalence in S. grammicus) have been found parasitizing the large intestine of amphibian and reptiles [89, 90]. The cestode Cyclophyllidea (9\% of prevalence in S. grammicus) uses a variety of insects as intermediate host. Ingestion of its eggs results in the development of a cysticercoid in the hemocoel that is infective to the ultimate host [91]. Particularly, the prevalence of this parasite is high in the Medium-3100 population, which might be also related with their low survival rates. Recent studies suggest that the environment alters the susceptibility to infections so that host infections depend on environmental conditions [92]. In general, the High-4150 population had the highest proportions of pathogens.

\section{Conclusions}

The bacterial phyla Firmicutes and Bacteroidetes and the genera Bacteroides and Parabacteroides dominated the core fecal bacteriome of $S$. grammicus. The fungal phyla Zygomycota and Ascomycota and the species Basidiobolus ranarum and $B$. magnus dominated the core fecal mycobiome. The diversity and quantity of the diet decreased dramatically for the lizards at high elevations. Considering the differences in diet, it was not surprising that the composition of the main microbial groups in the feces of $S$. grammicus was different at the three elevations, but not between female and male lizards. It is possible that dietary restriction in S. grammicus living at $4150 \mathrm{~m}$ explained the high fecal abundance of Akkermansia and Oscillopira, and the low temperature enriched B. magnus in the gut of the High- 4150 population. We detected important differences in the potential functions of the fecal bacteriome of $S$. grammicus in the three populations.

The bacterial diversity and richness were similar in $S$. grammicus along the altitudinal gradient. However, the Low-2600 population had a higher ITS phylotypes diversity than the two other populations and the main functions of its fungal community were digestive and hydrolytic as sufficient food intake promoted fungal diversity. We assume that the low survival rates of the Medium-3100 population might be related to the high prevalence of Cyclophyllidea and the low diversity of their resident microbiota.

\section{Supplementary information}

Supplementary information accompanies this paper at https://doi.org/10. 1186/s40168-020-0783-6.

Additional file 1: Table S1. Relative abundances and statistics for taxonomic groups identified through metabarcoding of the gene coxl that differed significantly (Kruskall-Wallis test) in abundance between three populations of Sceloporus grammicus along an altitudinal gradient.

\section{Acknowledgments \\ The authors thank M. Martínez-Gómez, "Estación científica La Malinche" and "Centro Tlaxcala de Biología de la Conducta" for access and logistic support. The authors thank Rodrigo Barrios and Erick Gómez and Miguel Domínguez for their support during the fieldwork.}

\section{Authors' contributions}

YEN-N and AHDV-P designed the study; AHDV-P conducted the fieldwork; NMM-C and SGA performed the molecular biology analysis; NMM-C, YEN-N, and LCM-A analyzed the sequences and data; YEN-N, AHDV-P, LD, and AE-T interpreted the data and wrote the manuscript; and all the other authors revised and edited the manuscript. All authors read and approved the final manuscript. 


\section{Funding}

This research was funded by Centro de Investigaciones y de Estudios Avanzados del IPN (CINVESTAV-IPN), Project Infraestructura 205945/ Consejo Nacional de Ciencia y Tecnología (CONACYT) and Catedras CONACyT program (project: 883). NM-C and LCM-A received postgraduate grant by CONACYT and SEG-A received a postdoctoral fellowship by CONACYT.

\section{Availability of data and materials}

All sequencing data are available from the National Center for Biotechnology Information (NCBI) Sequence Read Archive (SRA) under accession number PRJNA544140.

\section{Ethics approval and consent to participate}

This study was done with a permission of the "Secretaría de Medio Ambiente y Recursos Naturales" (SEMARNAT, Mexico) under the collecting permits: SGPA/DGVS/15396/15 and SGPA/DGVS/007736/18, and we followed the Official Mexican Norm NOM-126-ECOL-2000 as a guideline to handle the lizards.

\section{Consent for publication}

Not applicable.

\section{Competing interests}

The authors declare that they have no competing interests.

\section{Author details}

${ }^{1}$ Doctorado en Ciencias Biológicas, Centro Tlaxcala de Biología de la Conducta, Universidad Autónoma de Tlaxcala, Tlaxcala, México. ${ }^{2}$ Laboratory of Soil Ecology, Cinvestav, Mexico City, Mexico. ${ }^{3}$ Centro Tlaxcala de Biología de la Conducta, Universidad Autónoma de Tlaxcala, Tlaxcala, México.

${ }^{4}$ Cátedras CONACyT, Universidad Autónoma de Tlaxcala, Tlaxcala, México.

Received: 18 June 2019 Accepted: 1 January 2020

Published online: 24 January 2020

\section{References}

1. McFall-Ngai M, Hadfield MG, Bosch TC, Carey HV, Domazet-Lošo T, Douglas $A E$, Hentschel U. Animals in a bacterial world, a new imperative for the life sciences. Proc Nat Acad Sci USA. 2013;110:3229-36.

2. Round JL, Mazmanian SK. The gut microbiota shapes intestinal immune responses during health and disease. Nat Rev Immunol. 2009;9:313-23.

3. Heijtz RD, Wang S, Anuar F, Qian Y, Björkholm B, Samuelsson A, Pettersson S. Normal gut microbiota modulates brain development and behavior. Proc Nat Acad Sci USA. 2011;108:3047-52.

4. Semova I, Carten JD, Stombaugh J, Mackey LC, Knight R, Farber SA, Rawls JF. Microbiota regulate intestinal absorption and metabolism of fatty acids in the zebrafish. Cell Host Microbe. 2012;12:277-88.

5. Zarrinpar A, Chaix A, Yooseph S, Panda S. Diet and feeding pattern affect the diurnal dynamics of the gut microbiome. Cell Metab. 2014;20:1006-17.

6. Bestion E, Jacob S, Zinger L, Di Gesu L, Richard M, White J, Cote J. Climate warming reduces gut microbiota diversity in a vertebrate ectotherm. Nat Ecol Evol. 2017:8:161.

7. Reese AT, Dunn RR. Drivers of microbiome biodiversity: A review of general rules, feces, and ignorance. MBio. 2018;9:e01294-18.

8. Sinervo B, Méndez-de-la-Cruz F, Miles DB, Heulin B, Bastiaans E, VillagránSanta Cruz M, Lara-Resendiz R, Martínez-Méndez N, Calderón-Espinosa ML, Meza-Lázaro RN, et al. Erosion of lizard diversity by climate change and altered thermal niches. Science. 2010;328:894-9.

9. Hertz PE, Huey RB, Garland JT. Time budgets, thermoregulation, and maximal locomotor performance: are reptiles olympians or boy scouts? Am Zool. 1988;28:927-38.

10. Gillooly JF, Brown JH, West GB, Savage VM, Charnov EL. Effects of size and temperature on metabolic rate. Science. 2001;293:2248-51.

11. Ladyman M, Bonnet X, Lourdais O, Bradshaw D, Naulleau G. Gestation, thermoregulation, and metabolism in a viviparous snake, Vipera aspis: evidence for fecundity-independent costs. Physiol Biochem Zool. 2003;76: 497-510.

12. Leyte-Manrique A, Ramírez-Bautista A. Diet of two populations of Sceloporus grammicus (Squamata: Phrynosomatidae) from Hidalgo. Mexico. Southwest Nat. 2010;55:98-103.
13. Lemos-Espinal JA, Ballinger RE. Comparative thermal ecology of the highaltitude lizard Sceloporus grammicus on the eastern slope of the Iztaccihuat| volcano, Puebla. Mexico. Can J Zool. 1995;73:2184-91.

14. de la Cruz FR M, de la Vega-Pérez AH D, Centenero-Alcalá H, Jiménez-Arcos VH. Anfibios y Reptiles del Parque Nacional La Malinche. Universidad Autónoma de Tlaxcala; 2018. p. 138.

15. de la Vega-Pérez AH D, Barrios-Montiel R, Jiménez-Arcos VH, Bautista A, Bastiaans E. High-mountain altitudinal gradient influences thermal ecology of the Mesquite lizard Sceloporus grammicus. Can J Zool. 2019;97:659-68.

16. Kohl KD, Yahn J. Effects of environmental temperature on the gut microbial communities of tadpoles. Environ Microbiol. 2016;18:1561-5.

17. Han J, Guo R, Li J, Chen Y, Guan C, Zhao W. Organ mass variation in a toad headed lizard Phrynocephalus vlangalii in response to hypoxia and low temperature in the Qinghai-Tibet Plateau, China. PloS ONE. 2016;11:e0162572.

18. Zhang W, Li N, Tang X, Liu N, Zhao W. Changes in intestinal microbiota across an altitudinal gradient in the lizard Phrynocephalus vlangalii. Ecol Evol. 2018;8:4695-703.

19. Navarro-Noya YE, Suárez-Arriaga MC, Rojas-Valdes A, Montoya-Ciriaco NM, Gómez-Acata S, Fernández-Luqueno F, Dendooven L. Pyrosequencing analysis of the bacterial community in drinking water wells. Microb Ecol. 2013;66:19-29.

20. Sambrook J, Russell DW. Molecular cloning: A laboratory manual. 2nd ed. New York: Cold Spring Harb Laboratory Press; 1989.

21. Hoffman CS, Winston F. A ten-minute DNA preparation from yeast efficiently releases autonomous plasmids for transformation of Escherichia coli. Gene. 1987;57:267-72.

22. Klindworth A, Pruesse E, Schweer T, Peplies J, Quast C, Horn M, Glöckner FO Evaluation of general $16 \mathrm{~S}$ ribosomal RNA gene PCR primers for classical and next-generation sequencing-based diversity studies. Nucleic Acids Res. 2013; 41:e1.

23. Vargas Márquez F. Parques Nacionales de México. Aspectos físicos, sociales, legales, administrativos, recreativos, biológicos, culturales, situación actual y propuestas en torno a los Parques Nacionales de México. SEMARNAT. Instituto Nacional de Ecología, Mexico. 1997.

24. Rousk J, Bååth E, Brookes PC, Lauber CL, Lozupone C, Caporaso JG, Knight R, Fierer $\mathrm{N}$. Soil bacterial and fungal communities across a pH gradient in an arable soil. ISME J. 2010;4:1340-51.

25. Gardes M, Bruns TD. ITS primers with enhanced specificity for basidiomycetes - application to the identification of mycorrhizae and rust. Mol Ecol. 1993:2:113-8.

26. White TJ, Bruns T, Lee S, Taylor J. Amplification and direct sequencing of fungal ribosomal RNA genes for phylogenetics. In: PCR Protocols: A Guide to Methods and Applications. San Diego: Academic Press; 1990. p. 315-22.

27. Leray M, Yang JY, Meyer CP, Mills SC, Agudelo N, Ranwez V, Machida RJ. A new versatile primer set targeting a short fragment of the mitochondrial $\mathrm{COI}$ region for metabarcoding metazoan diversity: application for characterizing coral reef fish gut contents. Front Zool. 2013;10:34.

28. Geller J, Meyer C, Parker M, Hawk H. Redesign of PCR primers for mitochondrial cytochrome c oxidase subunit I for marine invertebrates and application in all-taxa biotic surveys. Mol Ecol Resour. 2013;13:851-61.

29. Edgar RC. Search and clustering orders of magnitude faster than BLAST. Bioinformatics. 2010;26:2460-1.

30. Wang Q, Garrity GM, Tiedje JM, Cole JR. Naive Bayesian classifier for rapid assignment of rRNA sequences into the new bacterial taxonomy. Appl Environ Microbiol. 2007;73:5261-7.

31. Köljalg U, Nilsson RH, Abarenkov K, Tedersoo L, Taylor AF, Bahram M, Douglas B. Towards a unified paradigm for sequence-based identification of fungi. Mol Ecol. 2013;22:5271-7.

32. Ma Z, Li L. Measuring metagenome diversity and similarity with Hill numbers. Mol Ecol Res. 2018:18:1339-55.

33. R Core Team. R: a language and environment for statistical computing. Vienna, Austria: R Foundation for Statistical Computing; R Foundation for Statiscal Computing; 2018.

34. Hamady M, Lozupone C, Knight R. Fast UniFrac: facilitating high-throughput phylogenetic analyses of microbial communities including analysis of pyrosequencing and PhyloChip data. ISME J. 2010;4:17-27.

35. Oksanen J, Blanchet FG, Friendly M, Kindt R, Legendre P, McGlinn D, Minchin PR, O'Hara RB, Simpson GL, Solymos P, et al. Vegan: community ecology package. R package version. 2017;2:4-3.

36. Kolde KR. Maintainer Raivo. Package 'pheatmap'. Version. 2015;1:0.8. Date: 2015-07-02 
37. Langille MG, Zaneveld J, Caporaso JG, McDonald D, Knights D, Reyes JA, Clemente JC, Burkepile DE, Vega Thurber RL, Knight R, et al. Predictive functional profiling of microbial communities using $16 \mathrm{~S}$ rRNA marker gene sequences. Nat Biotechnol. 2013;31:814-21.

38. McDonald D, Price MN, Goodrich J, Nawrocki EP, DeSantis TZ, Probst A, Andersen GL, Knight R, Hugenholtz P. An improved Greengenes taxonomy with explicit ranks for ecological and evolutionary analyses of bacteria and archaea. ISME J. 2012;6:610-8.

39. Kanehisa M, Sato $Y$, Kawashima M, Furumichi M, Tanabe M. KEGG as a reference resource for gene and protein annotation. Nucleic Acids Res. 2015;44:D457-62.

40. Parks DH, Tyson GW, Hugenholtz P, Beiko RG. STAMP: Statistical analysis of taxonomic and functional profiles. Bioinformatics. 2014;30:3123-4.

41. Godon JJ, Arulazhagan P, Steyer JP, Hamelin J. Vertebrate bacterial gut diversity: size also matters. BMC Ecol. 2016:16:12.

42. Hong PY, Wheeler E, Cann IK, Mackie RI. Phylogenetic analysis of the fecal microbial community in herbivorous land and marine iguanas of the Galapagos Islands using 165 rRNA-based pyrosequencing. ISME J. 2011;5:1461-70.

43. Yuan ML, Dean SH, Longo AV, Rothermel BB, Tuberville TD, Zamudio KR. Kinship, inbreeding and fine-scale spatial structure influence gut microbiota in a hindgut-fermenting tortoise. Mol Ecol. 2015;24:2521-36.

44. Costello EK, Gordon JI, Secor SM, Knight R. Postprandial remodeling of the gut microbiota in Burmese pythons. ISME J. 2010;4:1375-85.

45. Kohl KD, Brun A, Magallanes M, Brinkerhoff J, Laspiur A, Acosta JC, CaviedesVidal E, Bordenstein SR. Gut microbial ecology of lizards: insights into diversity in the wild, effects of captivity, variation across gut regions and transmission. Mol Ecol. 2017;26:1175-89.

46. Colston TJ, Jackson CR. Microbiome evolution along divergent branches of the vertebrate tree of life: what is known and unknown. Mol Ecol. 2016;25: 3776-800.

47. Keenan SW, Engel AS, Elsey RM. The alligator gut microbiome and implications for archosaur symbioses. Sci Rep. 2013:3:2877.

48. Jiang HY, Ma JE, Li J, Zhang XJ, Li LM, He N, Chen JP. Diets alter the gut microbiome of crocodile lizards. Front Microbiol. 2017:8:2073.

49. Hooper LV, Wong MH, Thelin A, Hansson L, Falk PG, Gordon Jl. Molecular analysis of commensal host-microbial relationships in the intestine. Science. 2001;291:881-4.

50. Arnesen JA, Małagocka J, Gryganskyi A, Grigoriev IV, Voigt K, Stajich JE, Henrik $H$. Early diverging insect-pathogenic fungi of the order entomophthorales possess diverse and unique subtilisin-like serine proteases. G3 (Bethesda). 2018;8:3311-9.

51. Mendoza L, Vilela R, Voelz K, Ibrahim AS, Voigt K, Lee SC. Human fungal pathogens of Mucorales and Entomophthorales. Cold Spring Harb Perspect Med. 2015:5:a019562.

52. Okafor II, Testrake D, Mushinsky HR, Yangco BG. A Basidiobolus sp. and its association with reptiles and amphibians in southern Florida. Sabouraudia. 1984:22:47-51.

53. Henk DA, Fisher MC. The gut fungus Basidiobolus ranarum has a large genome and different copy numbers of putatively functionally redundant elongation factor genes. PloS ONE. 2012;7:e31268.

54. Mishra P, Singh SK, Nilegaonkar SS. Extracellular chitinase production by some members of the saprophytic Entomophthorales group. Mycoscience. 2011;52:271-7.

55. Hoffmann C, Dollive S, Grunberg S, Chen J, Li H, Wu GD, Lewis JD, Bushman FD. Archaea and fungi of the human gut microbiome: Correlations with diet and bacterial residents. PloS ONE. 2013;8:e66019.

56. Wolfe KH, Armisen D, Proux-Wera E, OhEigeartaigh SS, Azam H, Gordon JL, Byrne KP. Clade-and species-specific features of genome evolution in the Saccharomycetaceae. FEMS Yeast Res. 2015;15.

57. Osimani A, Garofalo C, Milanović V, Taccari M, Cardinali F, Aquilanti L, Riolo P. Insight into the proximate composition and microbial diversity of edible insects marketed in the European Union. Eur Food Res Technol. 2017;243:1157-71.

58. Comitini F, Mannazzu I, Ciani M. Tetrapisispora phaffii killer toxin is a highly specific $\beta$-glucanase that disrupts the integrity of the yeast cell wall. Microb Cell Fact. 2009;8:55.

59. Chabé M, Lokmer A, Ségurel L. Gut protozoa: friends or foes of the human gut microbiota? Trends Parasitol. 2017;33:925-34.

60. Olson DM. The distribution of leaf litter invertebrates along a Neotropical altitudinal gradient. J Trop Ecol. 1994;10:129-50.

61. Sam K, Koane B, Jeppy S, Sykorova J, Novotny V. Diet of land birds along an elevational gradient in Papua New Guinea. Sci Rep. 2017;7:44018.
62. Sears MW. Resting metabolic expenditure as a potential source of variation in growth rates of the sagebrush lizard. Comp Biochem Physiol A Mol Integr Physiol. 2005;140:171-7.

63. Belzer C, De Vos WM. Microbes inside-from diversity to function: the case of Akkermansia. ISME J. 2012;6:1449-58.

64. Suzuki TA, Martins FM, Nachman MW. Altitudinal variation of the gut microbiota in wild house mice. Mol Ecol. 2018;28:2378-90.

65. Bai X, Lu S, Yang J, Jin D, Pu J, Moyá SD, Xu J. Precise fecal microbiome of the herbivorous tibetan antelope inhabiting high-altitude alpine plateau. Front Microbiol. 2018;28:2321.

66. Derrien M, Vaughan EE, Plugge CM, de Vos WM. Akkermansia muciniphila gen. nov. sp. nov., a human intestinal mucin-degrading bacterium. Int J Syst Evol Microbiol. 2004:54:1469-76.

67. Sonoyama K, Fujiwara R, Takemura N, Ogasawara T, Watanabe J, Ito H, Morita T. Response of gut microbiota to fasting and hibernation in Syrian hamsters. Appl Environ Microbiol. 2009;75:6451-6.

68. Konikoff T, Gophna U. Oscillospira: a central, enigmatic component of the human gut microbiota. Trends Microbiol. 2016;24:523-4.

69. Kohl KD, Amaya J, Passement CA, Dearing MD, McCue MD. Unique and shared responses of the gut microbiota to prolonged fasting: a comparative study across five classes of vertebrate hosts. FEMS Microbiol Ecol. 2014;90: 883-94.

70. Mackie Rl, Aminov RI, Hu W, Klieve AV, Ouwerkerk D, Sundset MA, Kamagata Y. Ecology of uncultivated Oscillospira species in the rumen of cattle, sheep, and reindeer as assessed by microscopy and molecular approaches. Appl Environ Microbiol. 2003;69:6808-15.

71. Kong Y, Teather R, Forster R. Composition, spatial distribution, and diversity of the bacterial communities in the rumen of cows fed different forages. FEMS Microbiol Ecol. 2010;74:612-22.

72. Campos P, Guivernau M, Prenafeta-Boldú FX, Cardona L. Fast acquisition of a polysaccharide fermenting gut microbiome by juvenile green turtles Chelonia mydas after settlement in coastal habitats. Microbiome. 2018;6:69.

73. Serrano-Cardozo VH, Lemos-Espinal JA, Smith GR. Comparative diet of three sympatric Sceloporus in the semiarid Zapotitlán Valley, Mexico. Rev Mex Biodivers. 2008;79:427-34.

74. Drechsler C. An odorous Basidiobolus often producing conidia plurally and forming some diclinous sexual apparatus. Am J Bot. 1964;51:770-7.

75. Fuentefria AM, Suh SO, Landell MF, Faganello J, Schrank A, Vainstein MH, Valente P. Trichosporon insectorum sp. nov., a new anamorphic basidiomycetous killer yeast. Mycol Res. 2008;112:93-9.

76. Criado-Fornelio A, Verdú-Expósito C, Martin-Pérez T, Heredero-Bermejo I, Pérez-Serrano J, Guàrdia-Valle L, Panisello-Panisello M. A survey for gregarines (Protozoa: Apicomplexa) in arthropods in Spain. Parasitol Res. 2017;116:99-110.

77. Karasov W, Douglas AE. Comparative digestive physiology. Compr Physiol. 2013;3:741-83.

78. Gouba N, Drancourt M. Digestive tract mycobiota: a source of infection. Med Mal Infect. 2015;45:9-16.

79. Hallen-Adams HE, Suhr MJ. Fungi in the healthy human gastrointestinal tract. Virulence. 2017;8:352-8.

80. Schweizer E, Hofmann J. Microbial type I fatty acid synthases (FAS): major players in a network of cellular FAS systems. Microbiol Mol Biol Rev. 2004;68:501-17.

81. Park MS, Lee S, Oh SY, Cho GY, Lim YW. Diversity and enzyme activity of Penicillium species associated with macroalgae in Jeju Island. J Microbiol. 2016:54:646-54.

82. Vishniac HS. Cryptococcus friedmannii, a new species of yeast from the Antarctic. Mycologia. 1985;77:149-53.

83. Białkowska AM, Szulczewska KM, Krysiak J, Florczak T, Gromek E, Kassassir H, Kur J, Turkiewicz M. Genetic and biochemical characterization of yeasts isolated from Antarctic soil samples. Polar Biol. 2017;40:1787-803.

84. Kohl KD, Dearing MD. Wild-caught rodents retain a majority of their natural gut microbiota upon entrance into captivity. Environ Microbiol Rep. 2014;6:191-5.

85. Wang W, Zheng S, Sharshov K, Sun H, Yang F, Wang X, Xiao Z. Metagenomic profiling of gut microbial communities in both wild and artificially reared Barheaded goose (Anser indicus). Microbiol Open. 2017;6:e00429.

86. Jackson J, Tinsley R. Effects of environmental temperature on the susceptibility of Xenopus laevis and X. wittei (Anura) to Protopolystoma xenopodis (Monogenea). Parasitol Res. 2002;88:632-8.

87. Pérez-Brocal V, Shahar-Golan R, Clark CG. A linear molecule with two large inverted repeats: the mitochondrial genome of the stramenopile Proteromonas lacerate. Genome Biol Evol. 2010;2:257-66. 
88. Hoevers JD, Snowden KF. Analysis of the ITS region and partial ssu and Isu rRNA genes of Blastocystis and Proteromonas lacertae. Parasitology. 2005;131: 187-96.

89. Bursey CR, Goldberg SR. Description of a new species of Paraphanyngodon (Nematoda: Pharyngodonidae) from Mexico with a list of current species and key to species from the Panamanian region. J Parasitol. 2015;101:374-81.

90. Pereira FB, Campião KM, Luque JL, Tavares LE. Parapharyngodon hugoi n. sp., a new nematode (Oxyuroidea: Pharyngodonidae) of the tree frog

Trachycephalus typhonius (Linnaeus) from the Brazilian Pantanal, including a key to the congeners from amphibians of the American continent. Syst Parasitol. 2017:94:599-607.

91. Bursey CR, Goldberg SR, Kraus F. New genus of Pharyngodonidae (Nematoda: oxyuridea) and other helminths in Platymantis nexipus (Anura: Ranidae) from Papua New Guinea. J Parasitol. 2009;95:669-72.

92. Wolinska J, King KC. Environment can alter selection in host-parasite interactions. Trends Parasitol. 2009;25:236-44.

\section{Publisher's Note}

Springer Nature remains neutral with regard to jurisdictional claims in published maps and institutional affiliations.

Ready to submit your research? Choose BMC and benefit from:

- fast, convenient online submission

- thorough peer review by experienced researchers in your field

- rapid publication on acceptance

- support for research data, including large and complex data types

- gold Open Access which fosters wider collaboration and increased citations

- maximum visibility for your research: over $100 \mathrm{M}$ website views per year

At BMC, research is always in progress.

Learn more biomedcentral.com/submissions 